WSRC-STI-2008-00141

\title{
Fracture Enhanced Soil Vapor Extraction Technology Demonstration at the A-014 Outfall
}

Brian D. Riha

W. Keith Hyde

SRNL

Richard Hall

South Carolina Universities Research and Education Foundation (SCUREF)

Clemson University

March 2008

Washington Savannah River Company, LLC

Savannah River Site

Aiken, SC, 29808

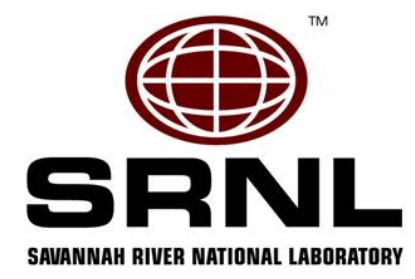

Prepared for the US Department of Energy under Contract DE-AC09-96SR18500 
This report was prepared by Washington Savannah River Company (WSRC) for the United States Department of Energy (DOE) under Contract No. DE-AC09-96-SR18500 and is an account of work performed under that contract. Every effort was made by the authors to assure the accuracy of the contents and interpretation. However, neither the DOE, nor WSRC, nor any of their employees makes any warranty, expressed or implied, or assumes any legal liability or responsibility for the accuracy, completeness, or usefulness of any information, apparatus, or product, or process disclosed herein, or represents that its use will not infringe privately owned rights. Reference herein to any specific commercial product, process, or service by trademark, name, manufacturer, or otherwise does not necessarily constitute or imply endorsement, recommendation, or favoring of same by the United States Government or any agency thereof. The views and opinions of the authors expressed herein do not necessarily state or reflect those of the United States Government or any agency thereof.

The methods presented in this document may be patented or patent pending through the United States Patent Office. 


\section{$\underline{\text { Contents }}$}

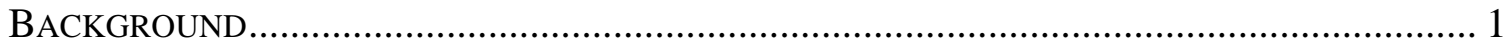

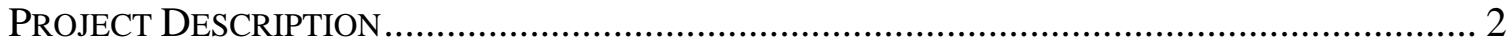

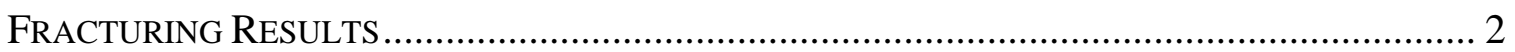

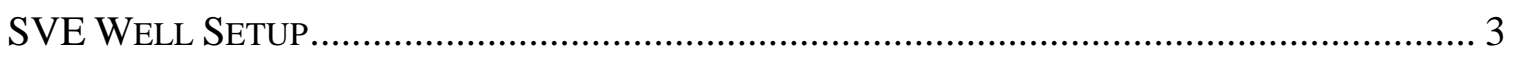

Fracture Well PERformance - Flow RATES ........................................................... 5

Fracture WeLl PERFormanCE - ZONE OF INFLUENCE ............................................. 7

CONCENTRATION TRENDS AND MASS REMOVAL .............................................................. 9

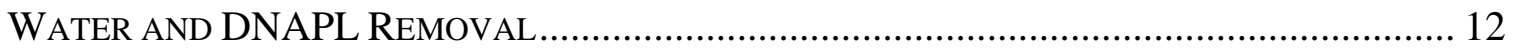

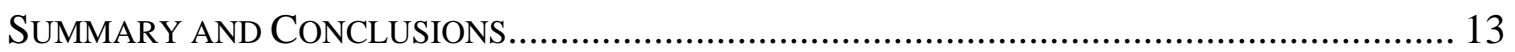

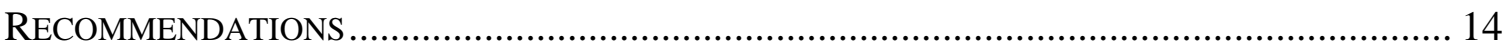

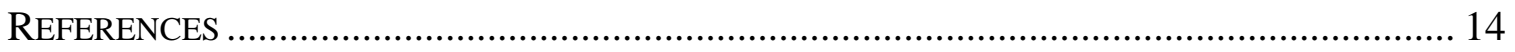

\section{$\underline{\text { List of Figures }}$}

Figure 1 - Plan View of the Well Locations .................................................................... 4

Figure 2 - Fracture Well Flow versus Pressure on 6/5/07 ........................................... 6

Figure 3 - Fracture Well Flow versus Pressure on 7/19/07 ........................................ 6

Figure 4 - Subsurface Vacuum Response during Flow Testing of Individual Fracture

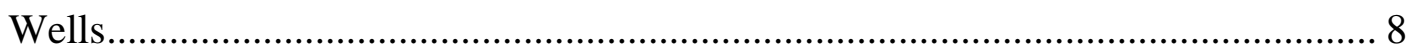

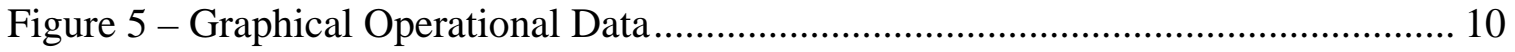

Figure 6 - Flow Rate, PCE Concentration and Rainfall for AF-2 and AF-4................... 11

Figure 7 - Mass Removed from 6/19/07 to 12/2/07 ....................................................... 12

\section{$\underline{\text { List of Tables }}$}

Table 1 - Summary of Fracture Injections ................................................................. 3

Table 2 - Decrease in Fracture Well Flow Rates ........................................................ 5

\section{Appendices}

Appendix A - Field Tests to Evaluate the A-14 Outfall SVE Fracture Wells Appendix B - A-014 Outfall Fracture Enhanced SVE Operational History Appendix C - A-014 Outfall Fracture Enhanced SVE Analytical and Operational Data 


\section{BACKGROUND}

M-Area process wastewaters were discharged from buildings in the M-Area to the A-014 Outfall from 1952 through 1980. It is estimated that 1.5 million pounds of chlorinated solvents may have been released to the A-014 Outfall through the sewer line. The majority of the solvents released was tetrachloroethylene (PCE) and to a lesser degree trichloroethylene (TCE). Small amounts of 1,1,1-trichloroethane (TCA) were also released.

Groundwater monitoring well data from the early 1980s indicated a cVOC (chlorinated volatile organic compound) source zone in the area of the present water discharge at the A-014 Outfall. The central sector groundwater recovery system includes well RWM-6, located adjacent to the outfall. Characterization work in the vadose zone was initiated in the early 1990s and a soil vapor extraction (SVE) remediation unit was put on-line in 1995.

The characterization work performed to date has shown that the majority of the vadose zone cVOC contamination associated with the outfall is located between 10 and 35 feet below the ground surface (Riha and Rossabi 2003). The solvent contamination is located in low permeability, fine-grained sediments that are difficult to remediate with traditional SVE, which is dependent upon moving large quantities of air through the vadose zone and the contaminated media.

Previous SVE testing in M-Area indicates that the shallow sediments have low air permeability. These sediments have historically produced flow rates less than $10 \mathrm{scfm}$ when tested with a traditional SVE system. Therefore, hydraulic fracturing was proposed to improve the permeability of these types of sediments, making them more suitable for treatment with traditional SVE. This fine grained zone is known as the Upland Unit and is fairly consistent in physical properties across the Savannah River Site A/M Areas.

The South Carolina Department of Health and Environmental Control (SCDHEC) granted the Savannah River Site (SRS) a Temporary Authorization (TA) to conduct a technology demonstration of fracture enhanced SVE at the A-014 Outfall (Haynes 2006). Fracture enhanced SVE is being used to remediate the shallow low permeability sediment contaminated with DNAPL (dense non-aqueous phase liquid) consisting cVOCs at the A014 Outfall. The Savannah River National Laboratory (SRNL) is performing the testing and evaluation of fracture enhanced SVE.

Polychlorinated biphenyls (PCBs) were present on the filter media from the SVE unit near the A-014 Outfall; and there is the possibility that PCBs are present in the area. Therefore, in December 2006 the SRS submitted a request for a modification to the riskbased Toxic Substances Control Act (TSCA) approval for the M-Area Settling Basin (MASB) Dynamic Underground Stripping (DUS) Project to allow the processing of the A-014 purge water through the MASB DUS Remediation System (Flora 2006). The MASB DUS Project contains a PCB treatment (filtering) system, referred to as the Mycelx Filter Skid. In May 2007, the U. S. Environmental Protection Agency provided 
approval to allow co-disposal of the contaminated purge water from the A-014 SVE process with the DUS effluent for treatment and disposal (Banister 2007).

\section{PROJECT DESCRIPTION}

The Savannah River Site (SRS) installed eight hydraulic fractured wells to enhance SVE for the treatment of solvent contamination in the Upland Unit at the A-014 Outfall at the Savannah River Site. A pilot study proving the value of SVE enhanced with soil fracturing was conducted in M-Area in FY05. Introducing propant-filled fractures into these tight zones improves the performance of SVE by 1) increasing the overall permeability of the formation and thereby increasing SVE flow rates, 2) shortening diffusion pathways, and 3) increasing air permeability by improving pore water removal. The synergistic effect of the fracture well completion methods, fracture and flow geometry, and pore water removal appears to increase the rate of solvent mass removal over that of increasing flow rate alone (Riha, Dixon et al. 2005).

PCE DNAPL is still present at the A-014 Outfall after years of SVE, which has only effectively treated the more permeable zones below the Upland Unit. This DNAPL zone is located directly beneath the original outfall infrastructure. The volume of soil containing DNAPL is approximately $50,800 \mathrm{ft}^{3}\left(1900 \mathrm{yd}^{3}\right)$. The DNAPL zone is approximately $20 \mathrm{ft}$ thick with a maximum depth of $35 \mathrm{ft}$. To reduce the long-term threat of this source area, SVE enhanced with soil hydraulic fracturing was initiated for the Upland Unit at the A-014 Outfall.

\section{FRACTURING RESULTS}

The fracture wells were constructed of 3.25 inch diameter Geoprobe push rods (fracture casing) with an annulus large enough for 2 inch schedule 40 PVC pipe. The fracture wells were installed in September 2006 by direct push techniques and the fracturing was completed in January 2007. Injections were done with the approval of Underground Injection Control Permit \#874.

The hydraulic fractures were created in a manner similar to that outlined in the document “Hydraulic Fracturing Technology, Technology Evaluation Report” (USEPA, 1993). Following this method, a radial notch was cut into the vadose zone sediments at the end of the fracture casing using a high pressure jetting tool referred to as a lance. This notch was used to initiate a hydraulic fracture. At the A-14 Outfall, the notches were made in a half circle towards the middle of the original outfall in an attempt to guide the fractures towards the source area (see Figure 1).

After the sediments were notched, a slurry of cross-linked guar gum gel and sand was injected at a constant flow rate into the 2-inch well using a progressive cavity pump. Injection was accomplished using a specialized mixer and pump operated by the subcontractor FRx, Inc. The purpose of the guar gum was to create a gel capable of suspending high concentrations of sand. An enzyme was added to the slurry to break 
down the gel several hours after injection. Once injection ceases, the resulting fracture starts to close as the gel seeps into the formation. The fracture is then held open by the sand (propant) that is left behind.

The injection pressure measured at the well-head increased abruptly to approximately 125 psi at the start of injection and then decreased as the fracture started to propagate. Pressure fluctuated during the first few minutes as the sand content in the gel was increased from small values up to the target load for the fracture. The pressure was typically in the range of 50 psi to 100 psi when the full load of sand in the slurry was being injected. Table 1 provides a summary of the results of the fracture injections. Five of the eight fractures were considered successful. Failures are attributed to the multitude of abandoned boreholes at the site from previous characterization and testing.

Table 1 - Summary of Fracture Injections

\begin{tabular}{|c|c|c|c|c|}
\hline $\begin{array}{l}\text { Well } \\
\text { ID }\end{array}$ & $\begin{array}{l}\text { Fracture } \\
\text { Depth, ft }\end{array}$ & $\begin{array}{c}\text { Fracture } \\
\text { Date }\end{array}$ & $\begin{array}{l}\text { Sand, } \\
\text { lbs }\end{array}$ & Comments \\
\hline AF-1 & 18 & $1 / 8 / 2007$ & 0 & $\begin{array}{l}\text { Vented to surface quickly at several } \\
\text { locations. This Fracture well could } \\
\text { not be salvaged. }\end{array}$ \\
\hline AF-2 & 26 & $1 / 4 / 2007$ & 2800 & Fracture installed as planned. \\
\hline AF-3 & 11 & $1 / 3 / 2007$ & 0 & $\begin{array}{l}\text { Vented to surface quickly at several } \\
\text { locations. This Fracture well could } \\
\text { not be salvaged. }\end{array}$ \\
\hline AF-4 & 23 & $1 / 4 / 2007$ & 2000 & $\begin{array}{l}\text { Bridged } 2 \text { times in either the hose or } \\
\text { well. Cleaned out and continued } \\
\text { injection. Fracture successful. }\end{array}$ \\
\hline AF-5 & 18 & $1 / 4 / 2007$ & 1800 & Fracture installed as planned. \\
\hline AF-6 & 11 & $1 / 4 / 2007$ & 0 & $\begin{array}{l}\text { Vented around annulus. Tried to add } \\
\text { grout to seal annulus. Retry on } \\
\text { 1/8/07 was unsuccessful }\end{array}$ \\
\hline AF-7 & 17 & $1 / 8 / 2007$ & 2000 & $\begin{array}{l}\text { Vented to surface at the very end of } \\
\text { injection. Fracture considered } \\
\text { successful }\end{array}$ \\
\hline AF-8 & 23 & $1 / 4 / 2007$ & 2800 & Fracture installed as planned. \\
\hline
\end{tabular}

\section{SVE WELL SETUP}

The five viable fractures were equipped for vapor extraction by flushing the remaining sand from the fracture casing and placing 2 inch diameter schedule 40 PVC pipe wells inside the casing. The wells had 10 slot $5 \mathrm{ft}$ screens with a bottom cap. Shrink tubing and a bead of vacuum grease were used to seal the steel casing and PVC well together. The seals were tested by placing a high vacuum on the well and checking for leaks with cigar smoke. 
The hydraulic fracture wells were completed with an atmospheric air inlet valve at the wellhead. Using a tee at the top of the wellhead, tubing was inserted down to the bottom of the wells and connected to the inlets. During long term testing the valves were controlled by solenoid valves that would open periodically to let atmospheric air flow in through the valve, down the tubing, and into the bottom of the well casing. This was done to increase air-flow velocity within the well casing to remove standing water that may accumulate during SVE operation.

The wells were connected to a manifold using cam-lock fittings and 2 inch flexible hose. A liquid ring vapor extraction unit equipped with a large capacity (2,000 gal) moisture knock-out tank was used to remove water and contaminants from the fractured sediments.

Additionally, two vertical arrays of monitoring points were installed to monitor the performance of the system. Each array consists of a Flexible Liner Underground Technology (FLUTe) liner equipped with six monitoring ports at $5 \mathrm{ft}$ intervals ranging from 10 to $35 \mathrm{ft}$ deep. Figure 1 provides the locations of the fracture wells and monitoring arrays.

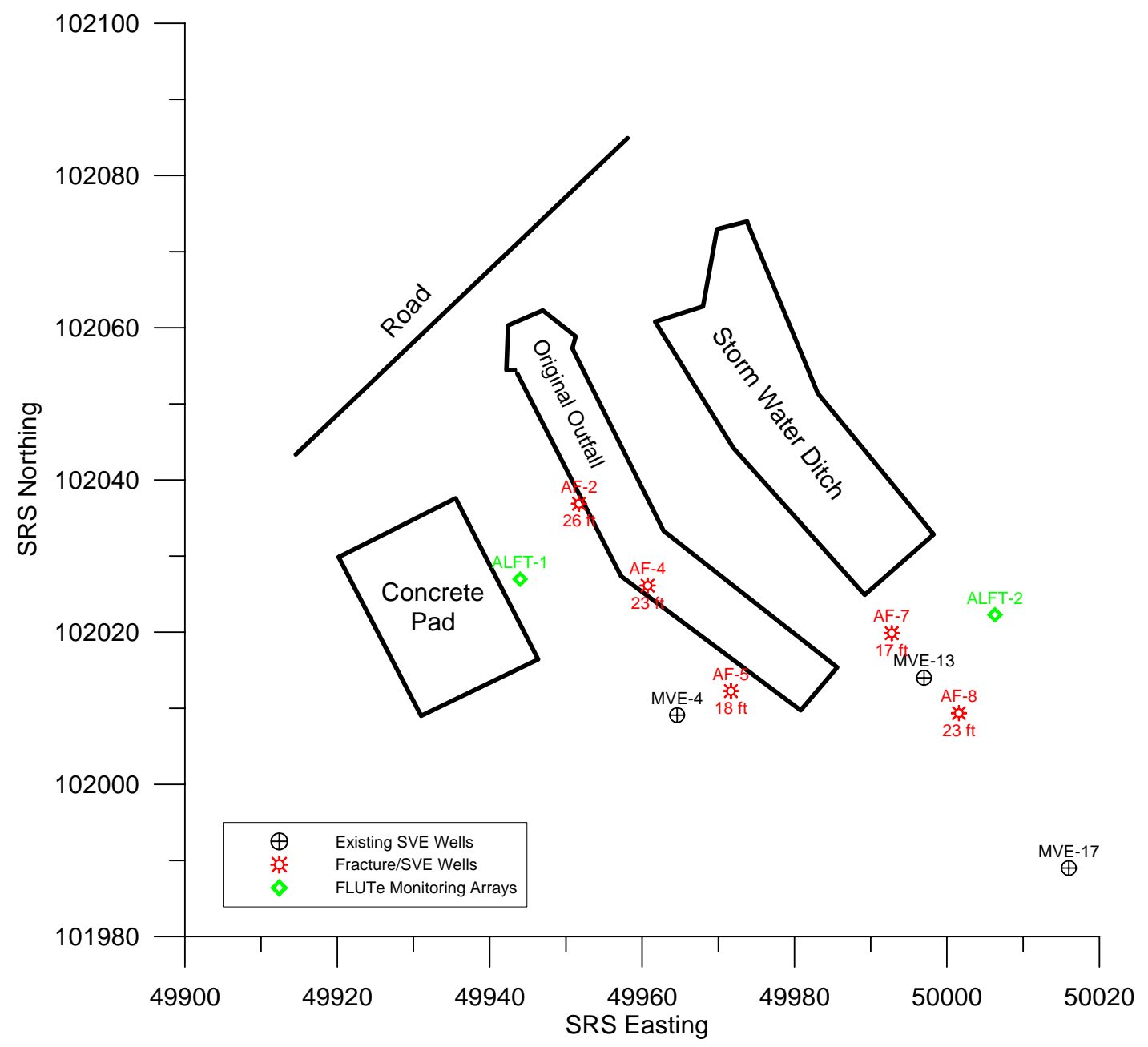

Figure 1 - Plan View of the Well Locations 


\section{Fracture Well Performance - Flow Rates}

The fracture wells were evaluated to determine flow characteristics and zone of influence. Flow measurements were made on each fracture well at three different pressures to evaluate the well flow performance. These tests were conducted on two different dates to evaluate any changes in the flow performance of the wells over time. The tests were conducted by running the SVE system at 5, 10, and 15 in Hg vacuum for 15 minutes each on each fracture well. The results of the two tests are presented graphically in Figure 2 and Figure 3. Note that well MVE-13 is also included in Figure 2. MVE-13 is a conventionally installed vertical well screened from $17-27 \mathrm{ft}$ and the data is used for comparison with the performance of the fracture wells. The flow rate for MVE-13 at 15 in Hg was 6.2 scfm.

Two sets of wells (AF-2, 4, 5 and AF-7, 8) were run continuously at maximum vacuum between these two flow tests. The flow rates decreased significantly for the majority of the wells except for AF-2 (Table 2).

Detailed discussions are provided on these field tests and some longer-term tests in Appendix A. The reason for the decrease in flow rate is a decrease in permeability. The reasons theorized for the decrease in permeability are primarily related to water infiltration and are listed below.

1. Increase in water saturation (decrease in relative permeability) due to increased rainfall between the two testing events.

2. Clogging of the fracture sand with fine grain materials due to liquefaction during high water saturations and high vacuums. Particularly fractures AF-5 and AF-7 that are located in the shallower fine-grained material.

Table 2 - Decrease in Fracture Well Flow Rates

\begin{tabular}{|c|c|c|c|}
\cline { 2 - 3 } \multicolumn{1}{c|}{} & \multicolumn{2}{c|}{$\begin{array}{c}\text { Flow Rate at 15 in } \\
\text { Hg, scfm }\end{array}$} \\
\hline $\begin{array}{c}\text { Fracture } \\
\text { Well ID }\end{array}$ & $6 / 5 / 2007$ & $7 / 19 / 2007$ & $\begin{array}{c}\text { Decrease in } \\
\text { Flow Rate }\end{array}$ \\
\hline AF-2 & 28.7 & 27.5 & $4 \%$ \\
\hline AF-4 & 17.3 & 9.5 & $45 \%$ \\
\hline AF-5 & 38.0 & 3.2 & $92 \%$ \\
\hline AF-7 & 4.1 & 1.4 & $66 \%$ \\
\hline AF-8 & 79.2 & 52.2 & $34 \%$ \\
\hline
\end{tabular}




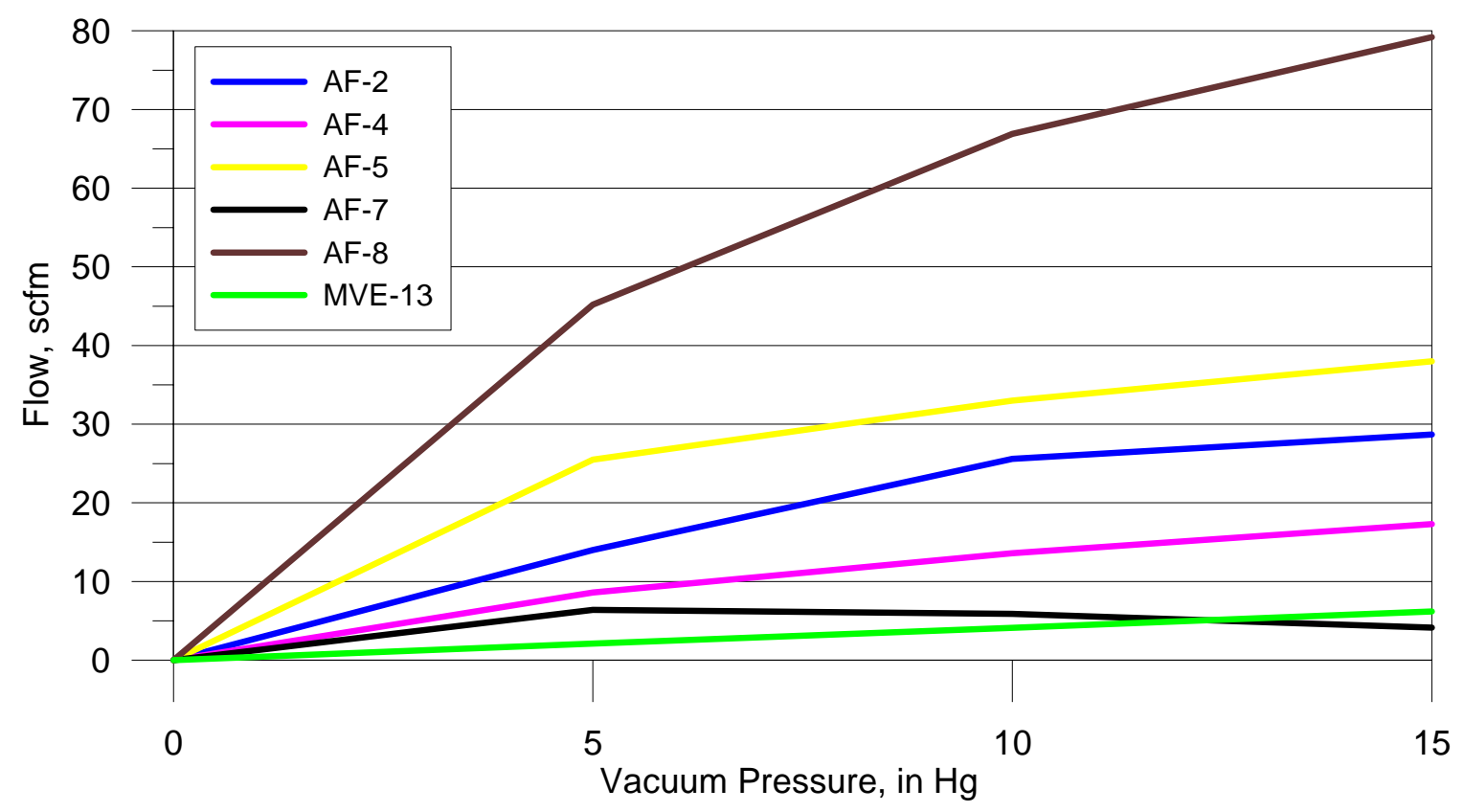

Figure 2 - Fracture Well Flow versus Pressure on 6/5/07

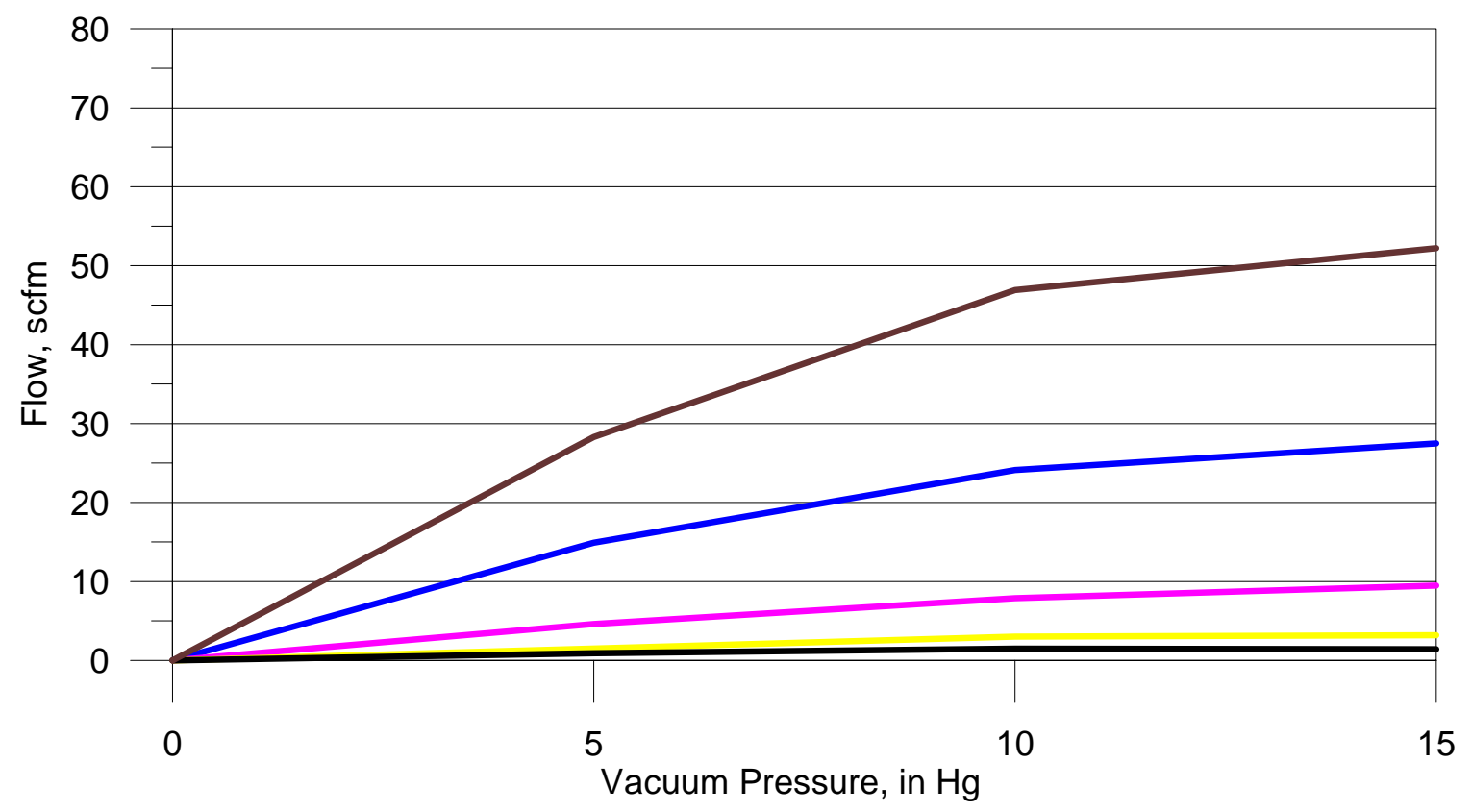

Figure 3 - Fracture Well Flow versus Pressure on 7/19/07 


\section{Fracture Well Performance - Zone OF INFLUENCE}

The zone of influence (ZOI) is defined here as a differential pressure between the extraction location (fracture) and other areas in the subsurface that would create air flow and mass removal. One can visualize a fracture SVE well as a horizontal disk or pancake in the subsurface with air-flow moving vertically (upwards and downwards) towards the fracture. Air-flow also occurs laterally towards the fracture due to the pressure gradients. Vertical cVOC removal was envisioned for the DNAPL source at the A-014 Outfall using the fractures, therefore, pressures were measured at $5 \mathrm{ft}$ depth intervals at two locations (AFLT-1 and 2). See location map in Figure 1 for fracture well and monitoring point locations.

Figure 4 provides subsurface vacuum pressure response from the four fracture wells that provided adequate flow for remediation (AF-2, 4, 5 and 8). The plots show the subsurface pressure at the two monitoring locations after 45 minutes of flow. The wells were tested individually at 15 in $\mathrm{Hg}$ vacuum. This data was collected during the 6/5/07 flow testing and provides a snapshot of the ZOI at that time but should provide a relative representation of the ZOI for each fracture. This data was used to illustrate the ZOI because the other SVE unit (3M) in the area was not operating. The 3M SVE unit would skew the vacuums in the deeper monitoring points since it is treating the sandy unit below the Upland Unit. The shaded region shows the depth of the fracture initiation. The fracture may dip upward or downward from the initiation point depending on the geology and previous borings nearby. The distance from the pressure monitoring points and fracture well (initiation point) is also shown on the plots.

Overall, each of the fractures show influence both vertically and laterally for moving air, water, and cVOCs towards the fractures for removal. The increasing vacuums with depth are due to the permeability increase with depth in the Upland Unit. The geologic setting is upper coastal plain where the Upland Unit was created in a fining upward depositional setting.

Fracture wells AF-2, 4 and 5 show the greatest influence for the vertical removal of the cVOCs in the source zone. The pressure gradients show the cVOCs will move both upward and downward towards the fractures for removal. These fractures are also closest to the main DNAPL source area. The ZOI will increase as the system is run constantly and under higher vacuum pressures.

The fracture wells show a significant lateral influence (up to $80 \mathrm{ft}$ ). No pressure response was seen in the monitoring points when testing the conventional vertical well (MVE-13) in the same formation and location (data not shown).

The mass transfer in the Upland Unit will be faster below the fractures and slower above the fractures due the permeability differences. Overall, the viable fracture SVE wells provide adequate coverage of the DNAPL source area for remediation. 


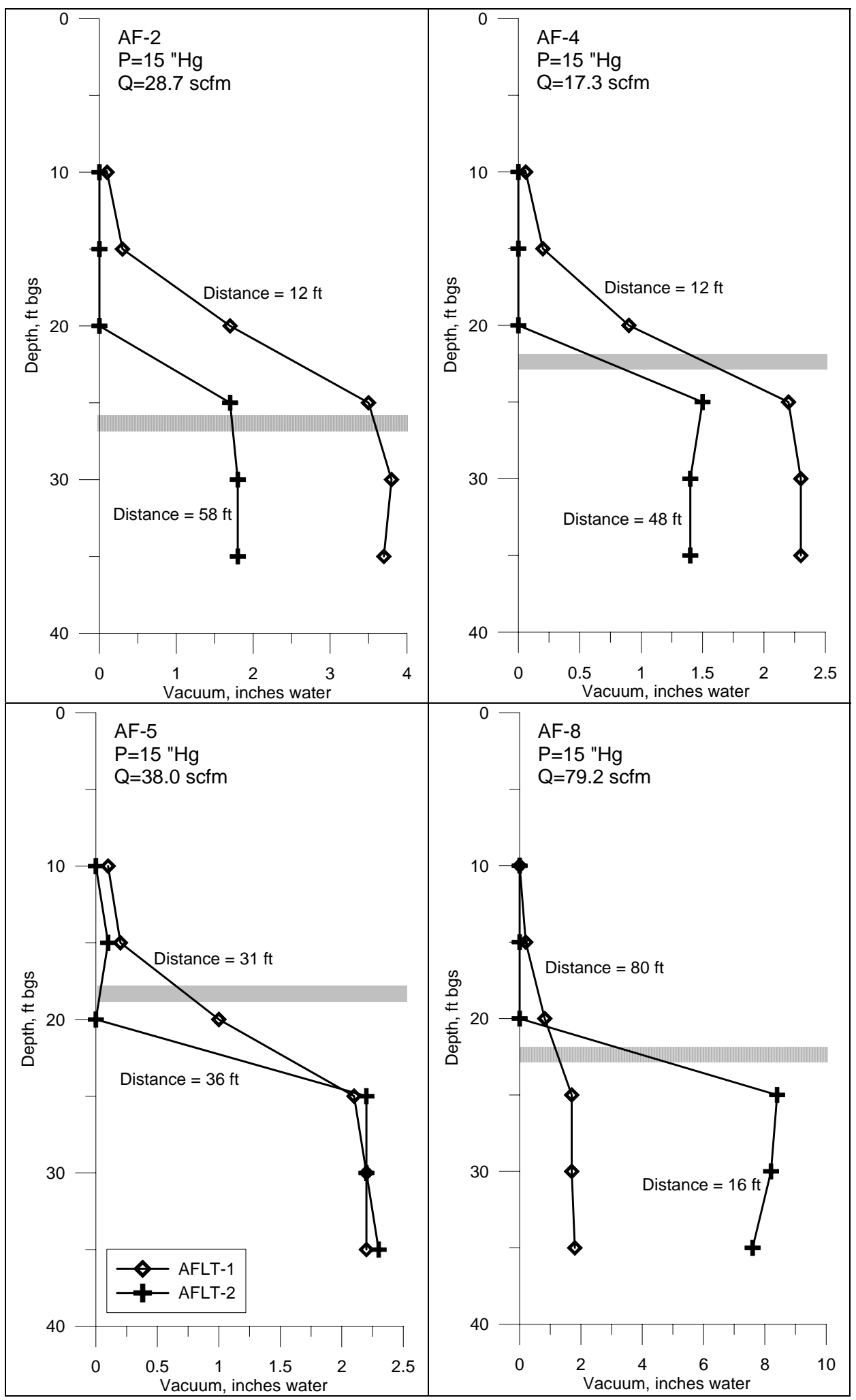

Figure 4 - Subsurface Vacuum Response during Flow Testing of Individual Fracture Wells 


\section{CONCENTRATION TRENDS AND MASS REMOVAL}

The SVE unit operated nearly continuously from 6/19/07 to 12/2/07 with several short down periods for maintenance. See operational history in Appendix B. The SVE system failed on 12/2/07 due to a failure of the drive shaft between the pump and motor that required the purchase and installation of a new pump and motor (the test unit was 12 years old at the time).

Tetrachloroethylene (PCE), trichloroethylene (TCE), and carbon dioxide $\left(\mathrm{CO}_{2}\right)$ concentration data were measured with an infrared photo-acoustic spectrometer (IRPAS). Additional gas chromatography (GC) analysis was also completed for air emission reporting. The IRPAS data corresponds well with the GC data. All analytical data is provided in Appendix $\mathrm{C}$ with a comparison of the IRPAS and GC data.

The operational data is provided graphically in Figure 5. The plot shows the flow and vacuum measurements, the start time for the different well configurations, the PCE concentration, and mass removal rates. Decreases in flow rate along with increases in vacuum are related to water movement towards the fractures and the resulting decrease in air permeability. 


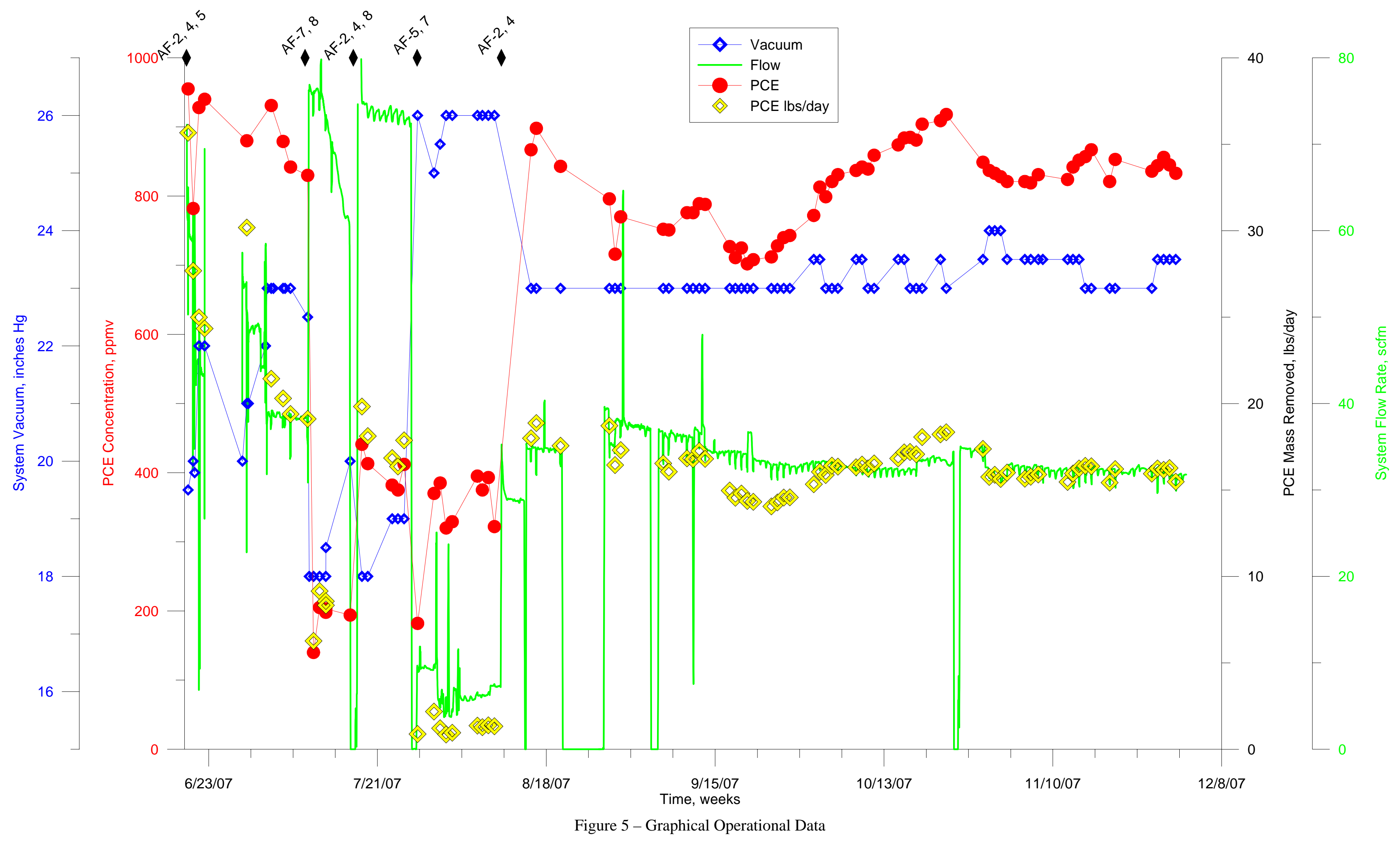


Figure 6 shows the PCE concentration, flow rate, and rainfall from 8/10/07 to 12/2/07 for fracture wells AF-2 and AF-4 to illustrate the influence of rainfall on the ZOI due to reduced relative permeability. A significant decrease in concentration is evident after rainfall events indicating a reduced ZOI in the contaminated area. The heart of the contaminated area is beneath the outfall that carries storm water runoff. The decrease in concentration is more likely a shift in the ZOI as air is removed from portions of the fractures that are not directly beneath the outfall. These portions of the fractures would receive less infiltration. However, the concentrations and ZOI rebound after a period of time following the rainfall events. The time it takes for the infiltrating water to influence the ZOI appears to be on the order of one week. The overall influence is related to the frequency of rainfall events. The rainfall from the middle of August to the middle of September decreased the PCE concentration by approximately $200 \mathrm{ppmv}$ ( $900 \mathrm{ppmv}$ to 700 ppmv or $22 \%$ ). The PCE concentration rebounded over the next month to 900 ppmv during low rainfall but decreased again during the next significant rainfall events. Overall, the flow rate was not affected significantly by rainfall for these two wells.
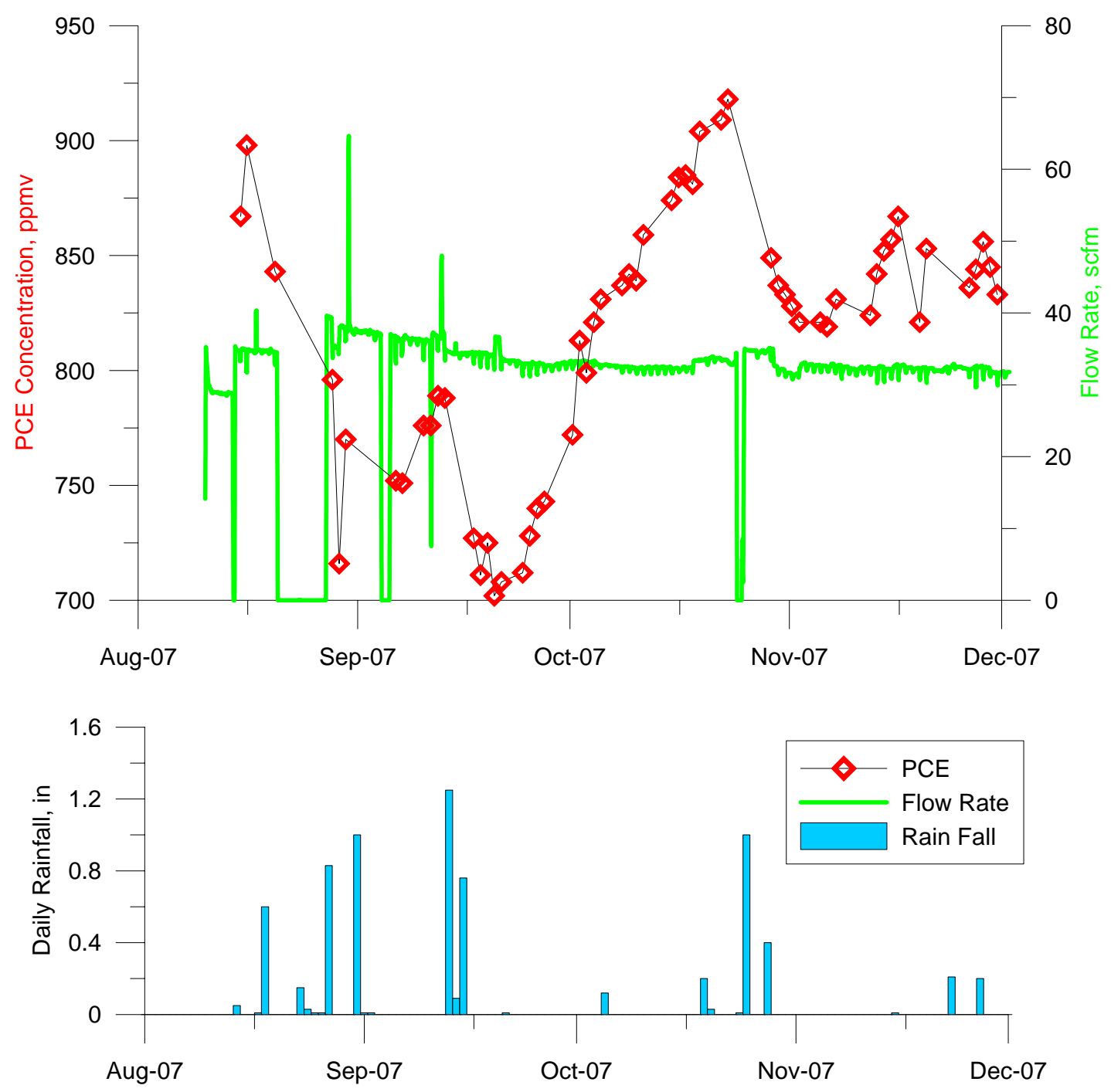

Figure 6 - Flow Rate, PCE Concentration and Rainfall for AF-2 and AF-4 
Mass removal was calculated from the concentration and flow data. The mass removed form 6/19/07 to 12/2/07 was 2,507 lbs PCE and 46.7 lbs TCE, and the cumulative mass removed over time is shown in Figure 7 . During this time period, the mass removal rate has changed with the rainfall events but rebounds after the ZOI recovers during dryer periods. The overall concentration and mass removal did not decline during this testing period, suggesting that the system removed the cVOCs from the source (DNAPL) area. Once this DNAPL source area becomes depleted, an exponentially declining concentration trend is expected.

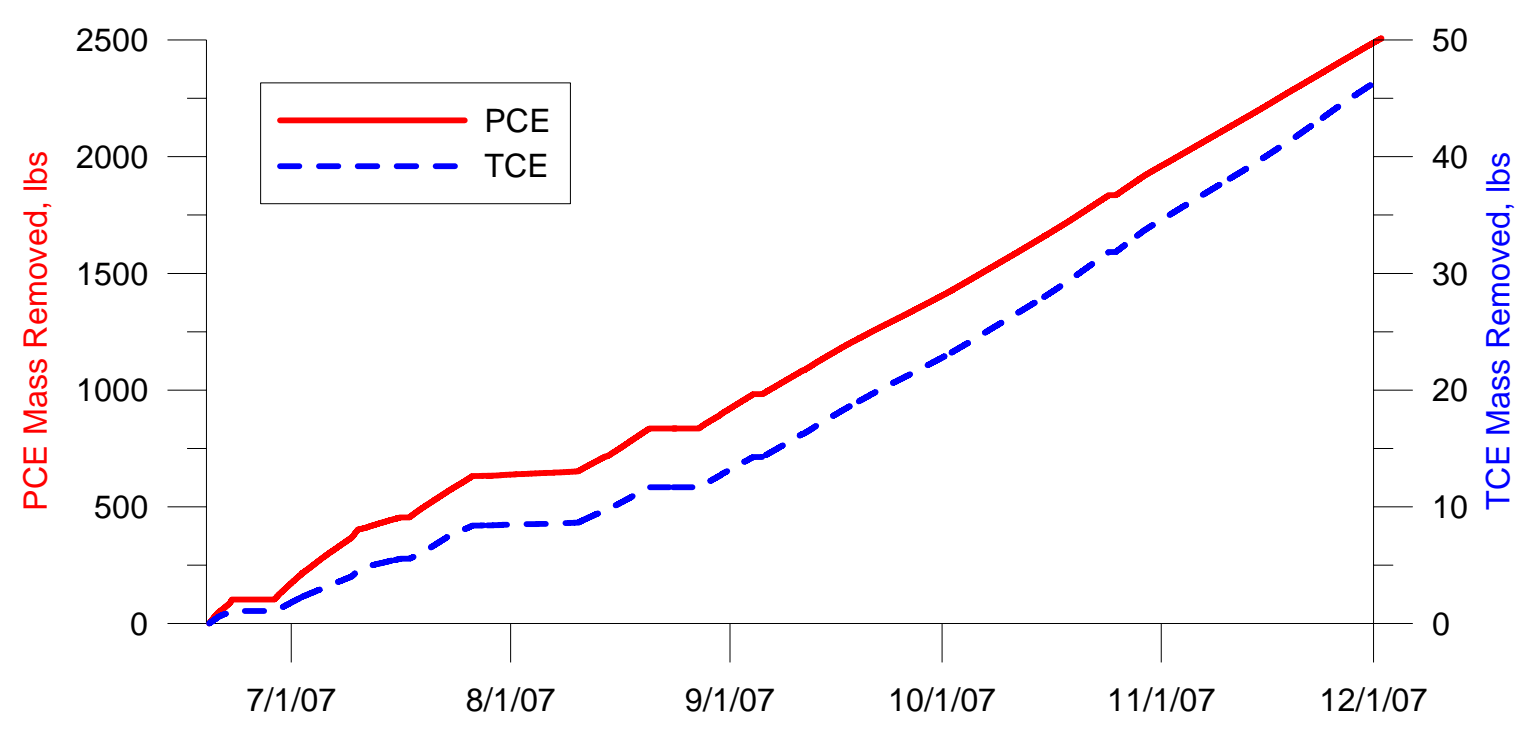

Figure 7 - Mass Removed from 6/19/07 to 12/2/07

\section{WATER AND DNAPL REMOVAL}

Water removal from the fracture wells was not measured directly because rainwater from the containment for the knockout tank was placed in the tank for disposal. The rainfall total in the area for the operating period was 21 inches and the containment was $12 \mathrm{ft} \mathrm{x}$ $12 \mathrm{ft}$. This results in approximately 1,900 gallons in the tank from rainfall. The tank contained approximately 2,000 gallons when emptied so approximately 100 gallons of pore water was removed from the fracture wells (ignoring evaporation of standing rainwater, which could be significant). Water removal from the fractures was expected to be greater, the reason for the low water removal from the fractures is unknown. DNAPL also was not observed in the tank.

It can be theorized that pore water moving into the fracture is draining downward prior to removal through the wells. This hypothesis is based on the observation of flow changes with rainfall (water is migrating towards the fractures) and the possibility of the fractures intercepting more conductive pathways for downward water migration. Several of the wells were observed to be sucking air due to the influence of SVE Unit 3M, indicating pathways to the sandy unit below the Upland Unit. This scenario is not necessarily detrimental since a soil vapor extraction well is operating in the sandy unit below the fracture zone to intercept any contaminants migrating downward with the water. 


\section{SUMMARY AND CONCLUSIONS}

Data collected during this study show that the performance of hydraulically fractured wells (with respect to mass removal rates) may tend to decrease with time following precipitation events. These effects are due to temporary increases in water saturation in the formation within the vicinity of the fractures, therefore, the wells should tend to rebound during subsequent dry periods. The data available for fractured well versus conventional well performance (with respect to flow rate versus vacuum pressure) are limited in this study. However, the data that we have to draw from suggest that, with the possible exception of a few extreme examples, hydraulically fractured wells tend to perform better than conventional wells during SVE operation at the A-14 Outfall.

The pancake like geometry associated with hydraulic fractures also leads to a significant increase in ZOI, as compared to conventional wells. The increase in ZOI is due to the radially extending, horizontal, high-permeability conduit nature of the hydraulic fracture, however, air-flow into the fracture is predominately vertical (occurring at right angles to the fracture plane). Flow rates from above and below the fracture will tend to be equivalent when the formation is homogeneous, however, in the case of directionally fining depositional sequences flow rates will be greater from the direction of increasing permeability. The Upland Unit is a fining upward sequence, therefore flow rates (and contaminant mass flow rates) will tend to be higher below the fracture. This suggests that emplacing the fractures slightly above the source zone is an important strategy for accelerating contaminant removal at the A-014 Outfall site and in the Upland Unit at the SRS. However, due to the multitude of previous borings at the A-014 Outfall site, the shallower fractures failed.

More than $2500 \mathrm{lbs}$ of cVOCs were removed during approximately 6 months of fractured well SVE operation at the A-014 field site. Plotting total mass removed over this time period shows a roughly linear relationship Figure 7 . This occurs because the mass removal rate remains fairly constant with time. When mass removal comes predominately from cVOCs stored in the vapor phase there is a marked decline in mass removal rate over a short period of time due to the limiting nature of diffusion. Constant mass removal rates suggest that a source zone has been directly targeted and, therefore, is providing a constant supply of cVOC that partitions into the vapor phase and is removed through the well. Directly targeting and removing source zones is the most efficient approach to remediating contaminated sites.

Results of this study show that utilization of hydraulic fractures during SVE is an effective approach for increasing remediation efficiency at the A-014 Outfall field site and in the Upland Unit at the SRS. Hydraulically fractured wells tend to produce greater flow rates and create larger ZOI's than do conventional wells. These attributes allow fractured wells to effectively treat larger volumes of formation. The unique sandemplacement geometry associated with hydraulically fractured wells also allows direct targeting of multiple zones located at similar elevations within a fairly large radius of the well. The ability to directly target source zones significantly decreases diffusion pathways, therefore, significantly decreasing the time required to reach remediation goals. 


\section{RECOMMENDATIONS}

The following recommendations are based on the data collected to date:

1. Continue operation of a high vacuum SVE unit on the fracture wells that are targeting the source area (AF-2, 4 and possibly 5) until mass removal rates begin to decline indicating source depletion. After source depletion, connect well AF-8. Although at a lower concentration, it should produce 5-8 lbs per day for a short period of time due to its high flow rate.

2. Perform periodic well performance testing to determine any degradation or improvement of the fracture wells and periodic ZOI testing to verify source area treatment coverage. The recommend frequency is semi-annually

3. Once the source zone depletion is indicated, evaluate more passive remediation techniques such as enhanced attenuation (EA) methods for finally polishing (i.e. edible oils and enhanced biodegradation)

\section{REFERENCES}

Banister 2007. Letter to Mary A. Flora regarding Toxic Substances Control Act (TSCA) risk-based polychlorinated biphenyl (PCB) disposal approval for the operation of the Western Sector Dynamic Underground Stripping (DUS) Project, Letter dated May 1, 2007

Flora 2006. Letter to Craig S. Brown regarding Modification to TSCA Approval for the M-Area Settling Basin Dynamic Underground Stripping Project: Temporary Authorization for the M-Area Hazardous Waste Management Facility Soil Hydraulic Fracturing Demonstration at the A-014 Outfall, Letter dated December 21, 2006

Haynes 2006. Letter to Mary A. Flora regarding Temporary Authorization Request: MArea Hazardous Waste Management Facility, Soil Hydraulic Fracturing Demonstration at the A-014 Outfall, WSRC-RP-2006-4039 Rev. 0 July 2006, Savannah River Site (SRS) SC1 890008 989, Aiken County, Letter dated August 24, 2006

Riha, B. D., K. L. Dixon and W. K. Hyde. 2005. Evaluation of Enhanced VOC Removal with Soil Fracturing in the SRS Upland Unit. Savannah River National Laboratory. Aiken, SC. WSRC-TR-2005-00415

Riha, B. D. and J. Rossabi. 2003. FY03 DNAPL Characterization of the A-14 Outfall. Savannah River National Laboratory. Aiken, SC. WSRC-TR-2003-00540

USEPA. 1993. Hydraulic Fracturing Technology, Technology Evaluation Report. USEPA Risk Reduction Engineering Laboratory, Office of Research and Development. Cincinnati, OH. EPA/540/R-93/505 


\section{Appendix A - Field Tests to Evaluate the A-14 Outfall SVE Fracture Wells Richard Hall (SCUREF, Ph. D. Candidate, Clemson University)}

Field tests were designed to characterize the performance of hydraulically fractured SVE wells located in the A-14 outfall area at SRS. Tests were conducted on five hydraulic fracture wells (AF-2,4,5,7,8) and a conventional well located in the test area that is part of a pre-existing SVE system (MVE-13) (Figure 1). Of the hydraulic fracture wells AF-5 and AF-7 were completed at relatively shallow depths (18 and $17 \mathrm{ft}$. respectively), whereas AF-2, 4, and 8 were deeper (26, 23, and $23 \mathrm{ft}$ respectively). Well MVE-13 is screened from 17 to 27 below ground surface. Multi-level monitoring wells were also installed (AFLT-1 and AFLT-2) with pressure ports located at depths of 10, 15, 20, 25, 30, and $35 \mathrm{ft}$ (Figure 1).

The hydraulic fracture wells were completed with an atmospheric air inlet valve at the well head. Tubing was inserted down to the bottom of the wells and connected to the inlets. During long term testing the valves were controlled by solenoid valves that would open periodically to let atmospheric air flow in through the valve, down the tubing, and into the bottom of the well casing. This was done to increase air flow velocity within the well casing to remove standing water that may accumulate during SVE operation.

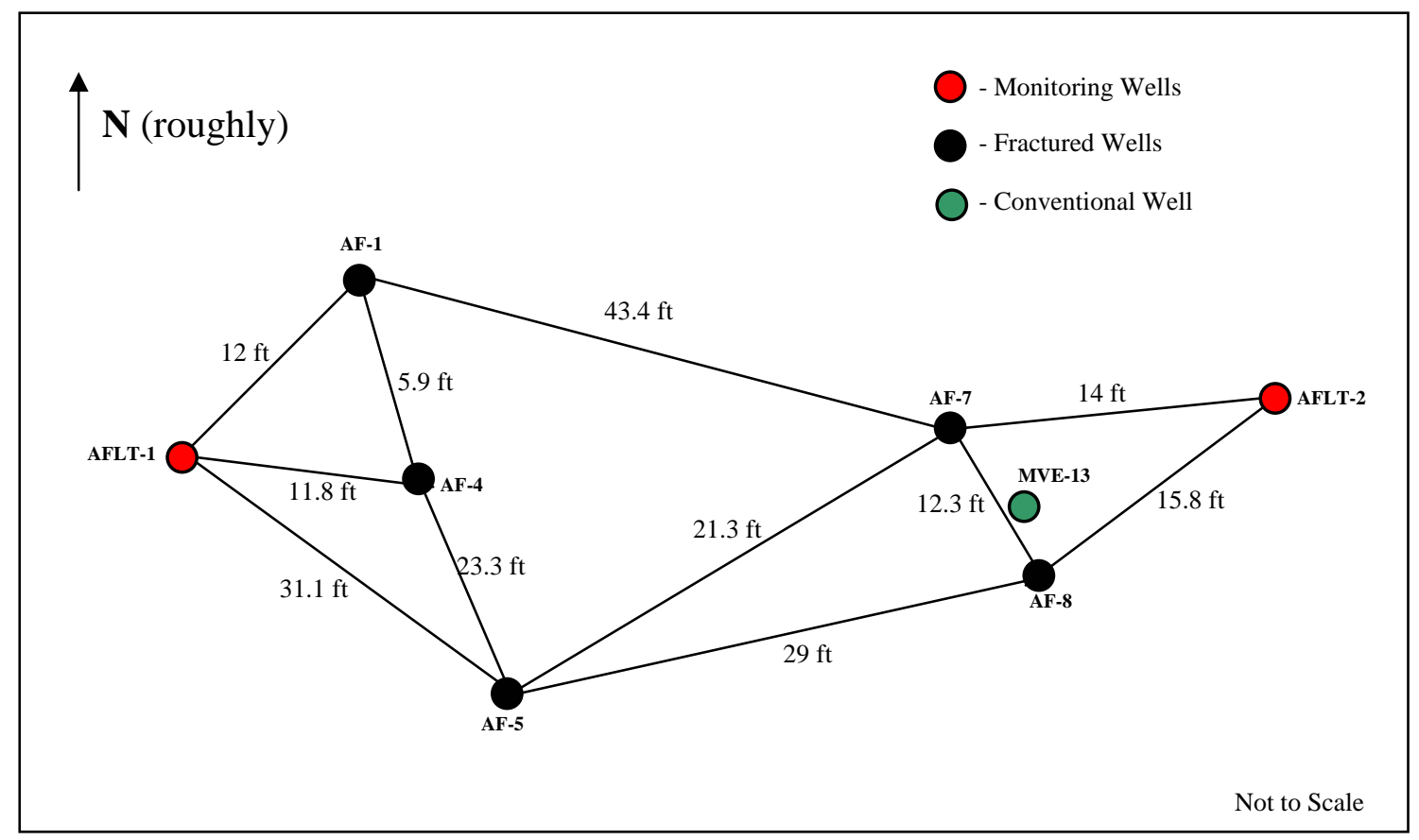

Figure 1- Locations of wells tested at A-14 field site.

Pressure step tests were designed to investigate the relationship between flow rate out of the well and applied vacuum. The subsurface pressure distribution induced around the wells during tests was also of interest, as this data could potentially provide information about formation properties and/or radius of influence. The pre-existing SVE system (3M) located at the field site was turned off at least 24 hours prior to the initiation of individual well tests to prevent pressure influences from other wells. 
Before any sequence of tests was initiated pressure readings were taken from the monitoring wells. If the pressure values measured were not equal to zero then the pressure readings obtained during testing were adjusted by that amount. This was done to ensure that the subsurface pressures analyzed resulted from stress induced by vacuum application and not from barometric pressure fluctuations.

The pressure step tests were conducted by applying constant vacuum over a period of 15 minutes while monitoring air mass-flow rate out of the well. Near the end of the 15-minute period pressure measurements were taken at each of the ports in the monitoring wells and in the surrounding fracture wells. The vacuum pressure was then increased and the process repeated. The tests were typically done using 3 vacuum pressures (5, 10, and 15 in Hg). After a test was completed the system was allowed to reequilibrate for half an hour before starting a test on another well.

\section{Well Test Results}

Well testing involved three phases. The first phase was conducted on 6-11-07 and consisted of a pressure step test on each of the wells. The second phase was conducted from 6-19-07 to 7-16-07. Phase 2 involved longer-term tests on selected wells that were manifold together while applying the maximum vacuum that the SVE unit was capable of producing. The third phase was conducted on 7-17-07 and consisted of repeating the pressure step test on each of the wells.

\section{Phase 1 Tests}

Results from the first pressure step tests conducted on 6-11-07 show that well AF8 performed better than any of the other wells by at least a factor or 2 ( $\sim 0$ scfm @ 15 in Hg vacuum), followed by wells AF-5 ( 38 scfm @ 15 in Hg vacuum), AF-2 ( 29 scfm @ 15 in Hg vacuum), and AF-4 ( 18 scfm @ 15 in Hg vacuum); with the conventional well (MVE-13) performing poorly as compared to the fractured wells ( 7 scfm @ 15 in Hg vacuum) (Figure 2). Well AF-7 showed anomalous behavior in that the flow rate actually decreased after increases in vacuum pressure (Figure 2). During the lowest vacuum portion of the test well AF-7 behaved similarly to well AF-4, but produced the lowest flow rate observed for any of the wells (including the conventional well) under 15 in Hg ( $\sim \mathrm{scfm})$. There do not seem to be any trends associated with flow rate verses either well completion depth, or volume of sand used to create the fractures.

With the exception of well AF-7, the way that flow rate increases with increasing vacuum pressure is similar for the fractured wells. Flow rate increases are greater for steps at lower pressures than for steps at higher pressures (Figure 2), suggesting that the flow rate increase with pressure may be asymptotic. However, the flow rate with pressure behavior for the conventional well differs in that flow rate increases approximately linearly (Figure 2). Similar differences in flow rate verses pressure relationships for fractured and conventional wells have been observed in previous work, and are thought to be the consequence of differences in air-flow geometry (Hall, 2005). 


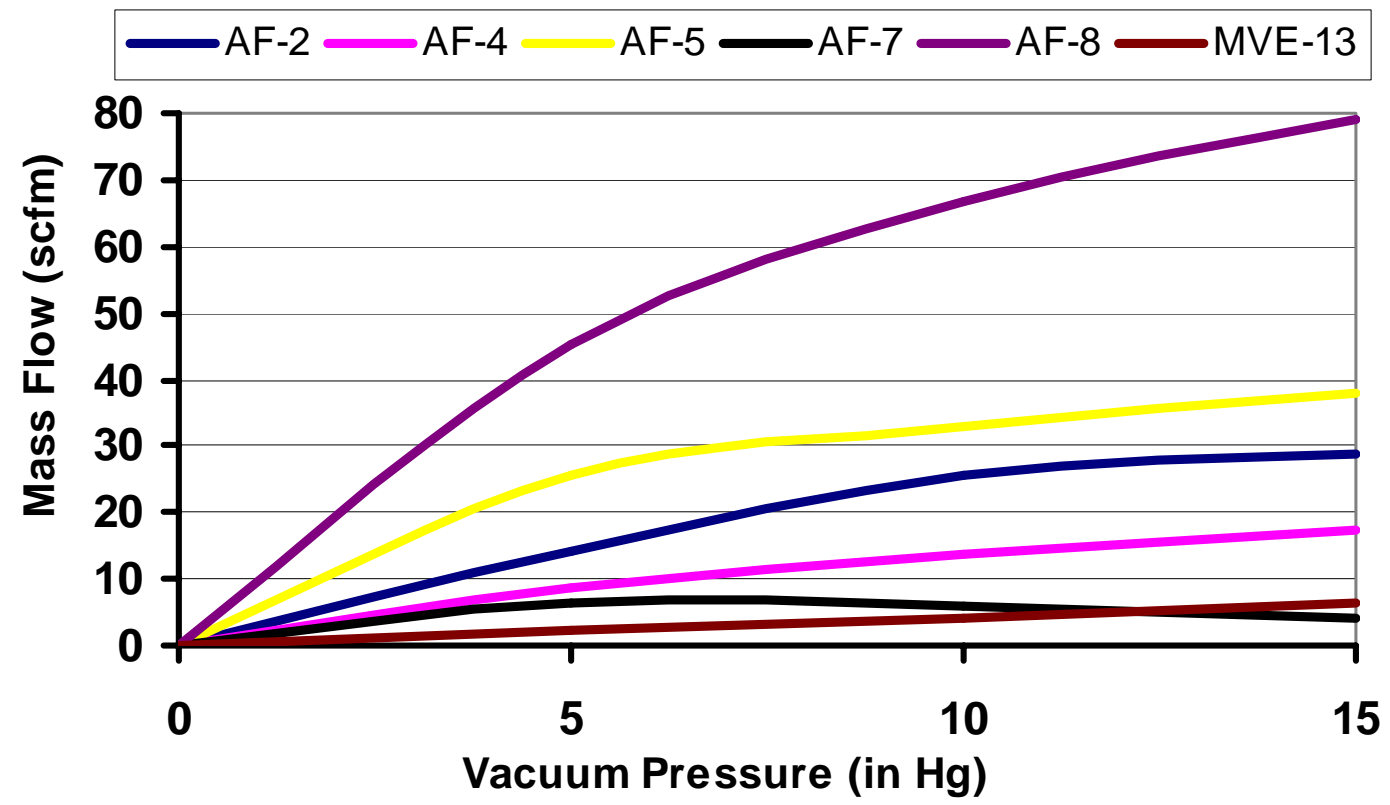

Figure 2- Results from pressure step tests conducted on 6-05-07.

Phase 2 Tests

Long term well tests conducted from 6-19-07 to 6-22 and from 6-28-07 to 7-0907 involved manifolding wells AF-2, 4, and 5. Wells AF-7 and 8 were manifolded for testing from 7-09-07 to 7-16-6-07. No testing was conducted from 6-22-07 to 6-28-28 due to equipment malfunction. Flow rate verses pressure data presented for phase 2 tests have been manually smoothed to remove spikes produced during gas sampling events. Dates on the x-axis correspond to the start of each day (midnight, 00:00)

During the longer-term tests the vacuum applied was the maximum that the SVE unit was capable of producing (air bypass valve on SVE unit was completely closed). Therefore when there was lesser resistance to flow (greater formation permeability, greater relative permeability, or the extreme case where the inlet is open to the atmosphere) then the vacuum pressure will be small and the air-flow rate will be large. However, when there is greater resistance to flow (lower formation permeability, lower relative permeability, or the extreme case where the inlet is plugged) then the vacuum pressure will be large and the air-flow rate will be small. Under these conditions there is a standard relationship between vacuum pressure and flow rate that is a function of the constant power produced by the SVE unit.

Tests conducted from 6-19-07 to 6-22-07 did not use solenoid valves on the atmospheric inlet valve; the valve was opened manually during sampling events to remove water from the well casings prior to sampling. Results from this test (Figure 3a) show that there was a fairly rapid decrease in flow rate (accompanied by the corresponding increase in vacuum pressure) during approximately the first hour of the test (flow started at $72 \mathrm{scfm}$ but not shown to accentuate other data). The flow rate then shows an increase as a result of activities associated with a sampling event 1 (opening atmospheric valves to remove water) that took place at 14:30 on 6-19-07. After sampling event 1 the flow rate again decreased for approximately 5 hours then stayed fairly 
constant for approximately 14 hours. The flow rate then increases during sampling event 2 that occurring around 10:30 on 6-20-07 and, following a short term decrease, the flow rate remained fairly constant for a period of approximately 5 hours. Sampling event 3 occurred at 16:40 on 6-20-07 and marked the start of a rapid decrease in flow rate (31\% decrease) over a period of approximately 6 hours. The flow rate then begins to rebound again, however, subsequently decreases after sampling events 4 and 5 at 9:30 and 13:45 on 6-21-07. The test was then disrupted due to equipment malfunction.

a)
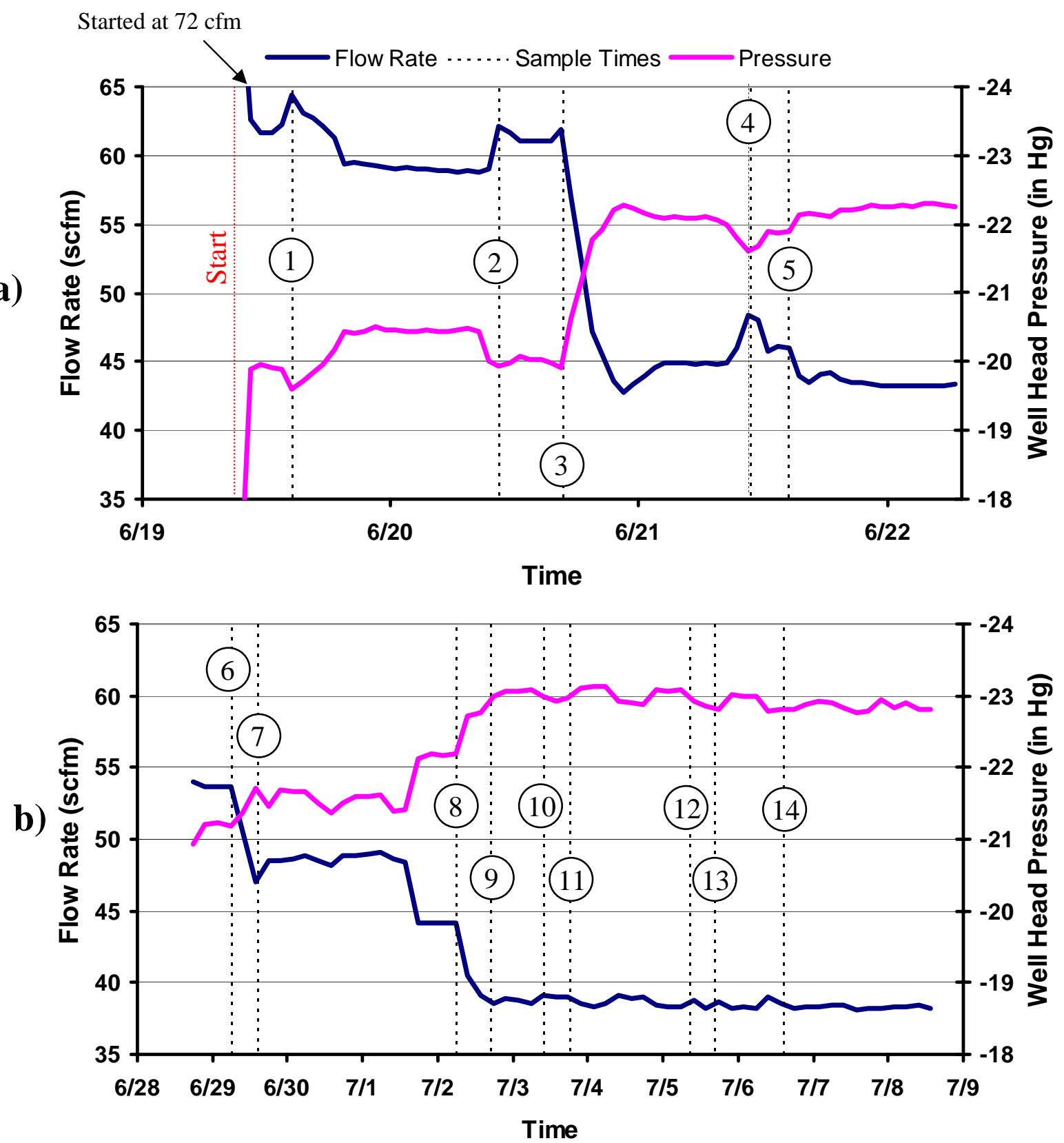

Figure 3- Results from Phase 2 tests with Wells AF-2, 4, and 5 manifolded.

a) 6-19 to 6-22 and b) from 6-28 to 7-09 (Sampling events are numbered in circles) 
The AF-2, 4, 5 test was restarted on 6-28-07 with the solenoid valves installed and set to open every 45 minutes (Figure 3b). The flow rate at the start of the test was greater than flow rate at the end of the previous test ( $54 \mathrm{scfm}$ as opposed to $\mathrm{s} 43 \mathrm{cfm}$ ), which is to be expected because the system had time to re-equilibrate (re-pressurize). The flow rate, however, was significantly less than the initial flow rate of the first test (54 scfm as opposed to $72 \mathrm{scfm}$ ), which suggests some type of change in the system.

From 6-28-07 to 7-03-07 the flow rate decreases (Figure 3b). As seen during the first test (Figure 3a), abrupt decreases in flow rate seem to correlate with sampling events. The only exception is a sampling event that occurred at 14:30 on 6-29-07 where flow increased for a short time afterwards. The flow rate decreases to a point and becomes fairly constant starting around 7-3-07. At this point the responses of flow rate to sampling events stopped occurring. There is, however, a small magnitude cyclic pattern in the data that continues until the end of the test (more visible in pressure data). This is probably either due to solenoid valve dewatering activity or, more likely, due to fluctuations in barometric pressure.

Beginning on 7-9-07, a long-term test on wells AF- 7 and 8 was conducted. The flow rate with time data shows that sampling events caused the increase followed by decrease in flow rate pattern observed during the previous long-term tests on wells AF 2, 4, and 5. However, the flow rate data shows a fairly smooth, nearly linear decrease over the 7 day period if these sampling "blips" are ignored (accompanied by the corresponding nearly linear increase in vacuum pressure) (Figure 4). This pattern is most visible during the 7-14-07 to 7-16-17 portion of the test over which samples were not taken (Figure 4).

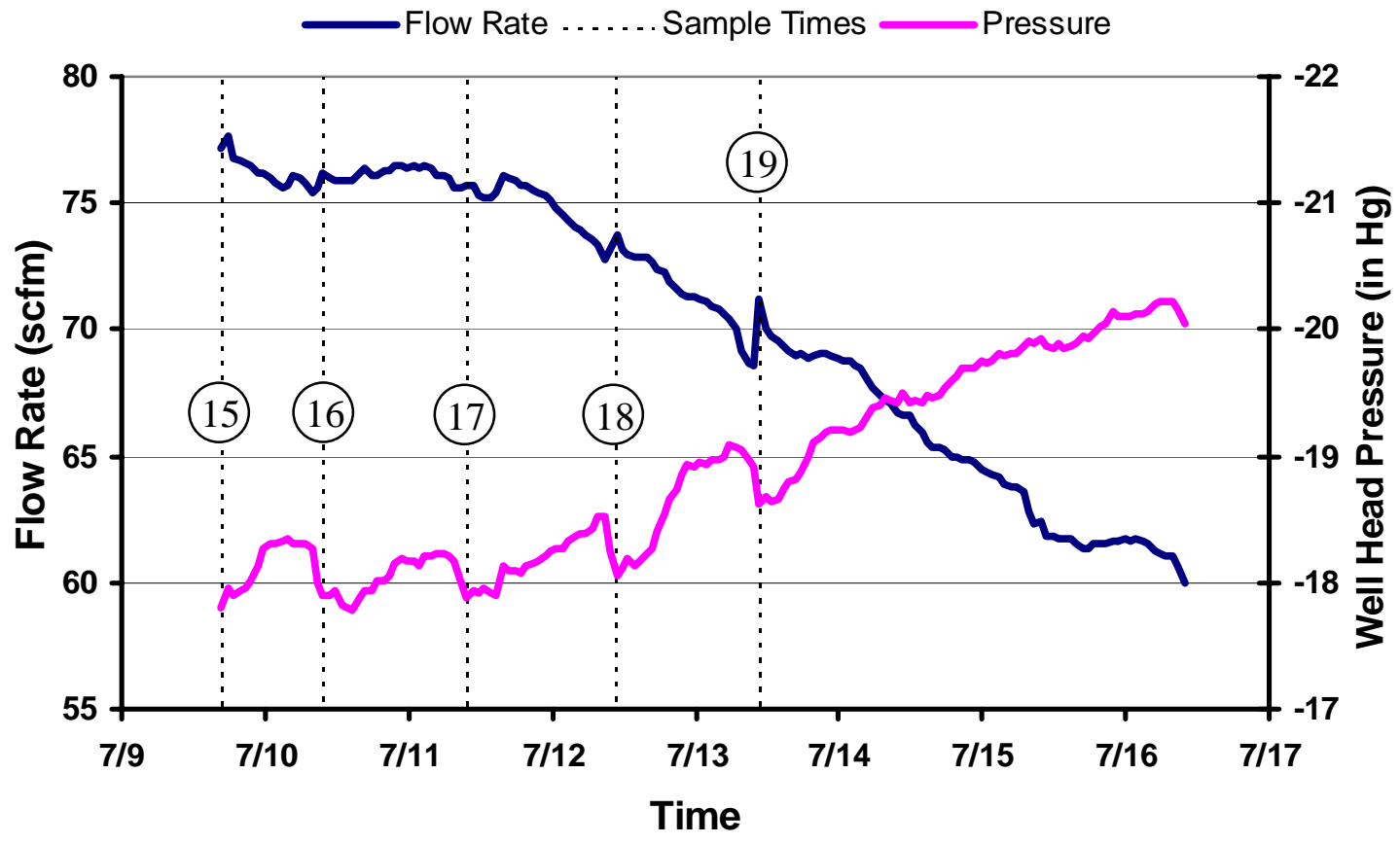

Figure 4- Results from Phase 2 tests with Wells AF-7 and 8 manifolded.

(Sampling events are numbered in circles) 
WSRC-STI-2008-00141

Appendix A

Phase 3 Tests

Results from the second round of pressure step tests conducted on 7-19-07 show that well AF- 8 again performed better than any of the other wells by nearly a factor of 2 ( 52 scfm@15 in Hg vacuum), followed by wells AF-2 ( 28 scfm @15 in Hg vacuum), and AF-4 ( 10 scfm @ 15 in Hg vacuum), and AF-5 ( 3 scfm @ 15 in Hg vacuum) (Figure 5). Well AF-7 again showed anomalous behavior in that the flow rate decreased as higher vacuum pressures were applied, and was again the worst performer of the fractured wells (Figure 2). Phase 3 test data for well MVE-13 is unavailable due to a problem during testing (well shutoff valve was closed).

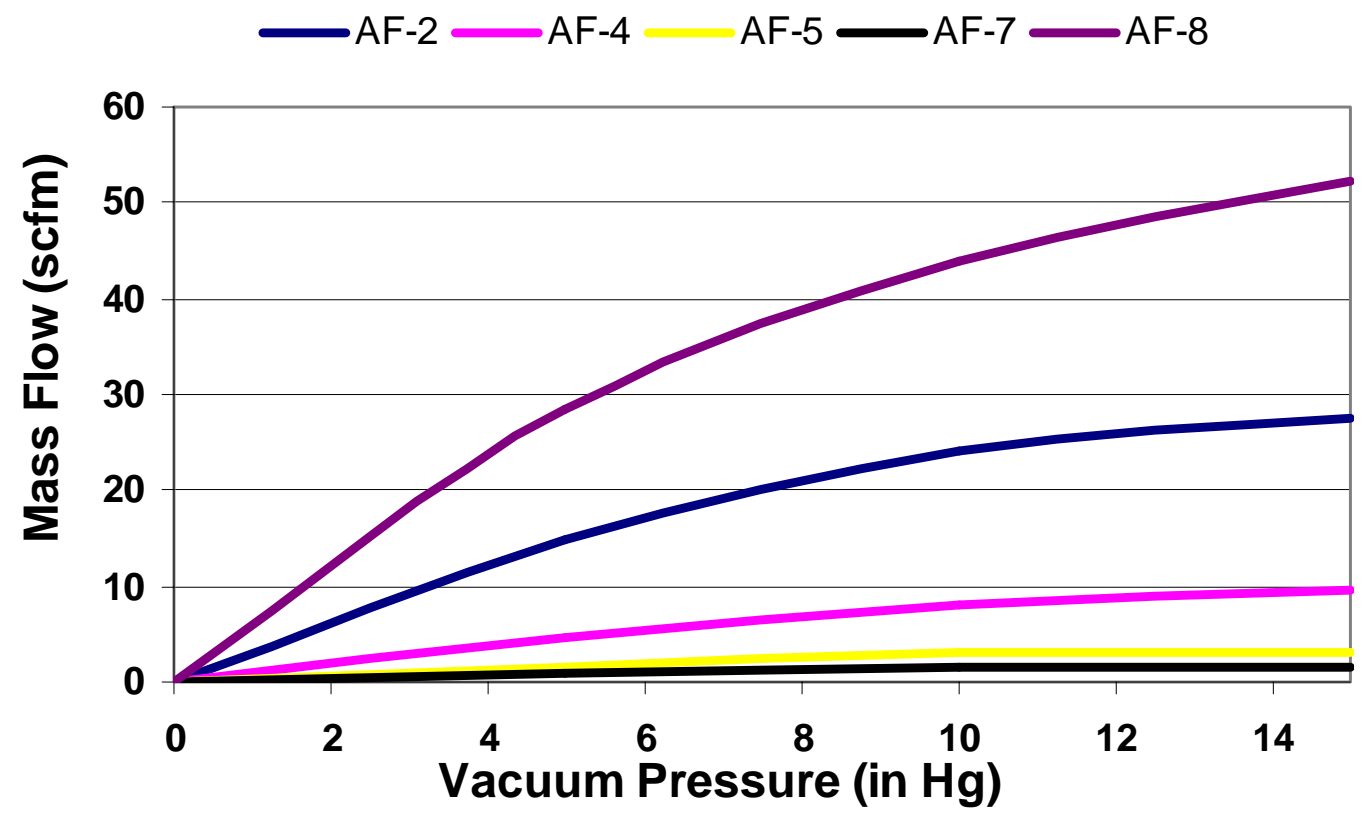

Figure 5- Results from pressure step tests conducted on 7-19-07. (Notice difference in y-axis for figures 2 and 5).

The well performance rankings from Phase 1 and Phase 2 are similar, with the exception of well AF-5. AF-5 was the second best performing well during the 6-11-07 pressure step tests, however, the ranking decreased to second from last during the 7-1907 tests. While Well AF-5 was an extreme case, the flow rates at various vacuum pressures decreased for all of the wells (Figure 6). Well AF-2 showed the smallest decrease in flow rate (4\%); the AF-2 result plots from the different tests are actually very similar (Figure 6). Wells AF-4, 7, and 8 showed intermediate decreases in flow rate (45\%, 66\%, and 34\% respectively). Well AF-5 was the extreme case with a 92\% reduction in flow rate (Figure 6). 
WSRC-STI-2008-00141

Appendix A
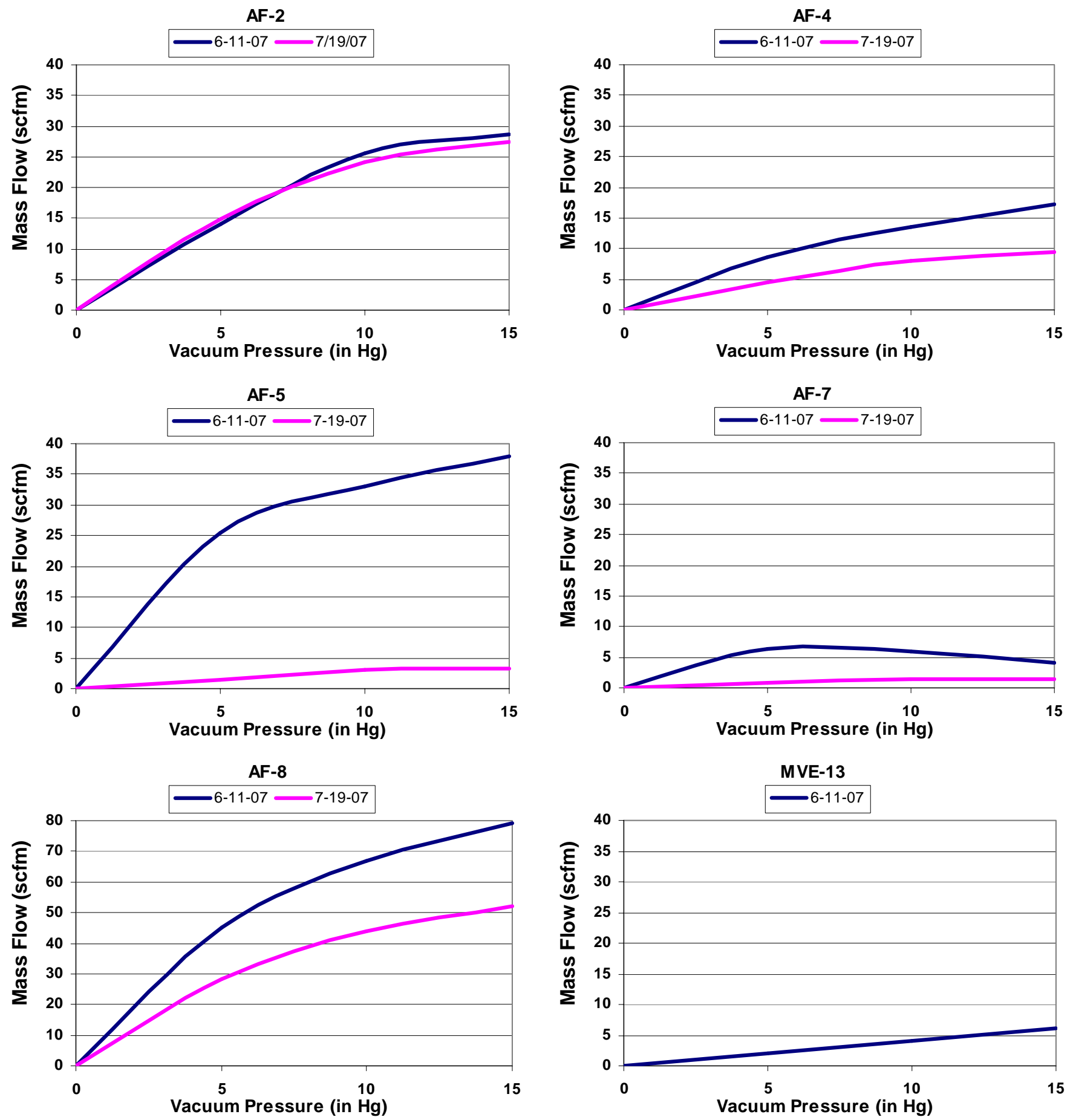

Figure 6- Comparison of 6-11-07 and 7-19-07 test results for all wells. (Notice AF-8 plot y-axis is different from others) 


\section{Discussion}

When a vacuum is applied to an SVE well the flow rate will start out high and then decrease with time to some equilibrium mass flow rate. The pressure within the formation around the well screen is roughly atmospheric prior to the start of vacuum pumping. When pumping is initiated the pressure within the formation around the well screen decreases as air flows into and out of the well. Much of the air produced during early vacuum pumping is removed from formation storage in this way. As pumping continues the pressure front created by the SVE well migrates greater distances away from the well screen (radius of influence increases with time). The rate at which subsurface pressure changes decreases with time as air mass from atmospheric influences (or other open wells) becomes the primary source of air flow to the well. This continues until an equilibrium radius of influence/vacuum pressure condition is reached (Figure 7). This equilibrium is reached when the air mass supplied from the surrounding subsurface and atmosphere becomes equal to the air mass produced from the well.

Abrupt fluctuations in flow rate and vacuum pressure observed during phase 2 testing can mostly be attributed to sampling events. Prior to sampling, each of the manifolded wells was isolated under maximum vacuum and the atmospheric air inlet valve was opened to remove water from the well casing. Opening the atmospheric inlet valve causes a large increasing spike in flow rate along with a large decreasing spike in vacuum pressure (these are the spikes that were removed during the data smoothing process). The act of opening the wells to the atmosphere also has the effect of increasing the pressure (decreasing the vacuum) to some degree within the formation around the well screen. The partial re-pressurization along with the fact that water may have been removed from the well casing accounts for the increase in flow rate associated with some sampling events (evident in sampling events 1, 2, 3, 4, 16, 18, and 19 (Figures 3 and 4)).

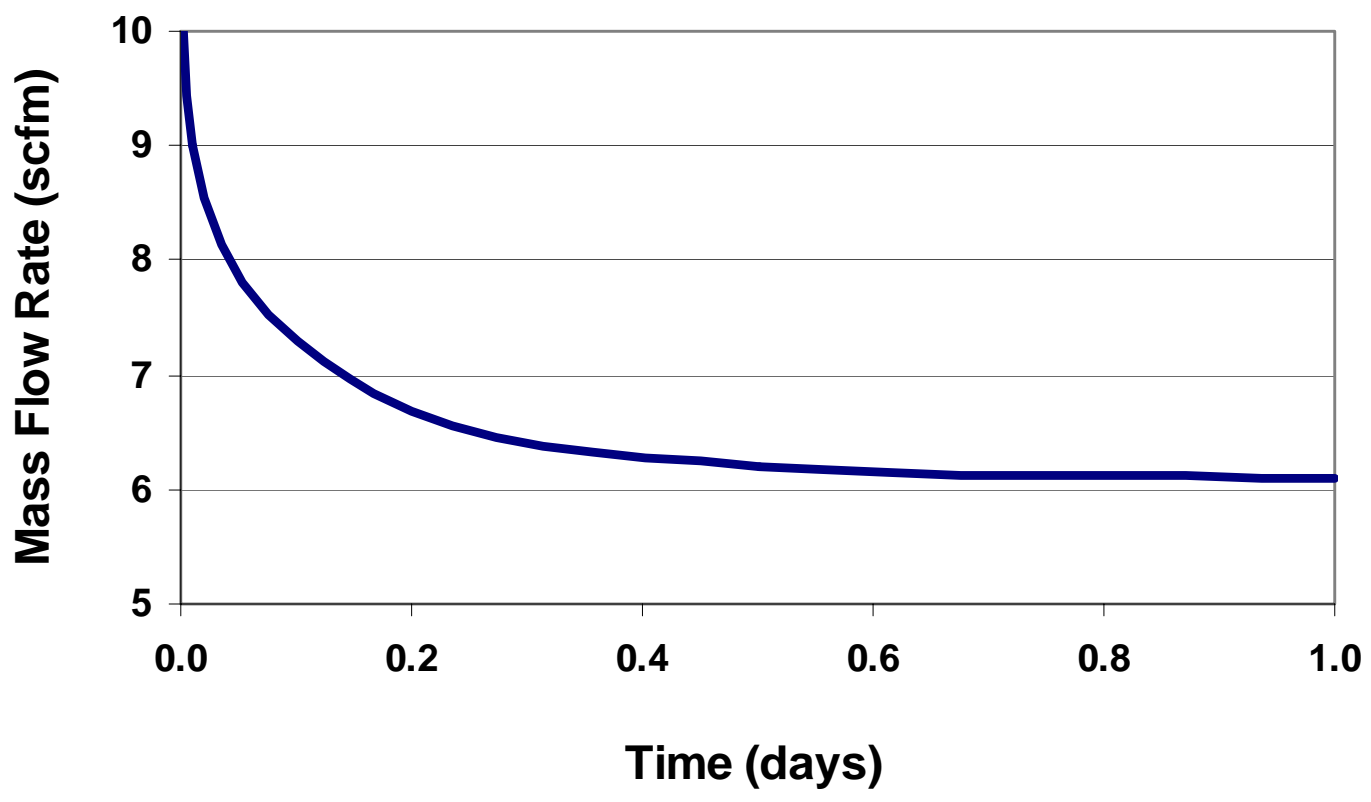

Figure 7- Results of constant vacuum simulation showing tendency of flow rate to decrease with time during SVE operation. 
The sampling and dewatering processes typically cause an increase in flow rate, however, it is expected that the flow rate should decrease over a fairly short period of time following the sampling event as the system goes back to equilibrium. Theoretically it should return back too, or near too the pre-sampling flow rate and then continue following whatever trend was present (typically decreasing or constant). However, according to phase 2 field test data this was not always the case. Following the post sample re-equilibration period for the AF-2, 4, 5 tests the flow rates were significantly decreased for sampling events $1,3,5,6$, and 8 (as compared to the pre-sampling flow rates) (Figure 3a,b). In contrast, flow rates were increased after the re-equilibration period for sampling events 2, 4, and 7 (Figure 3a,b). Sampling events 9 through 14 occurred during a period when the system seems to have reached an equilibrium condition, and did not significantly effect flow rate one way or the other (Figure 3b).

Results from the AF-7, 8 phase 2 test were more representative of what would be expected theoretically (Figure 4). There is a general decrease in flow rate during the test that is to be expected to some extent as the system goes to equilibrium. However, there may be another process responsible for some of the decrease as it is roughly linear in the field test data, whereas, decrease to equilibrium under constant conditions is a negative exponential (Figure 7). In any case, the data trend and flow rate were reasonably resumed following the disruptions induced by sampling events (Sample events 18 and 19 are good examples) (Figure 4).

During the phase 2 tests the tendency was for flow rate to decrease either gradually (Figure 4) or abruptly (Figure 3, following sampling event 3). As described before a negative exponential (gradual) decrease is expected early, however, this property of expected flow transience does not seem to account for all of the flow reduction observed during phase 2 tests. This becomes evident when considering the fact that the flow rates observed during the 7-19-07 pressure step tests were consistently less than those observed during the 6-11-07 tests (Figure 6). In each case the system (subsurface) was not stressed in any way at least 24 hours prior to testing. Obtaining consistently differing results from the two sets of tests suggests that some systematic change in the system occurred during the period of time between the tests. The most pressing questions put forth by these results are: What caused the systematic decrease in well performance for the fractured wells? and What caused the particularly extreme decrease in well performance of well AF-5 and the anomalous behavior of well AF-7?

The most plausible explanation for decrease in flow rate would be a decrease in permeability (or relative permeability) of the formation or the material filling the hydraulic fractures. A decrease in relative permeability would occur due to an increase in formation water saturation. This is a distinct possibility considering that during the 2 month period leading up to the first round of tests there was relatively little rain fall, however, the period just before and during the testing phase were comparatively rainy (Figure 8). A particularly heavy 3-day rain event occurred a week prior to the initial tests, and it also rained the day before the initial tests (Figure 8). The infiltration rates at the test site are probably fairly slow, considering the moderate to low permeability of the upper 4 to $5 \mathrm{ft}$ of the upland unit. The formation material located at depths near the hydraulic fractures may have been relatively dry due to lack of rainfall during the previous 2 months, which would facilitate high flow rates during the first round of tests. By the time that the second round of tests were conducted the infiltrating water may have 
had adequate time to reach the fracture depths and decrease relative permeability, and thus decrease flow rates during the second round of tests. The phase 2, long-term tests were conducted between the two rounds of pressure step tests. Application of high vacuum to the wells over this period would have expedited the infiltration of water near the surface to the depths around the hydraulic fractures.

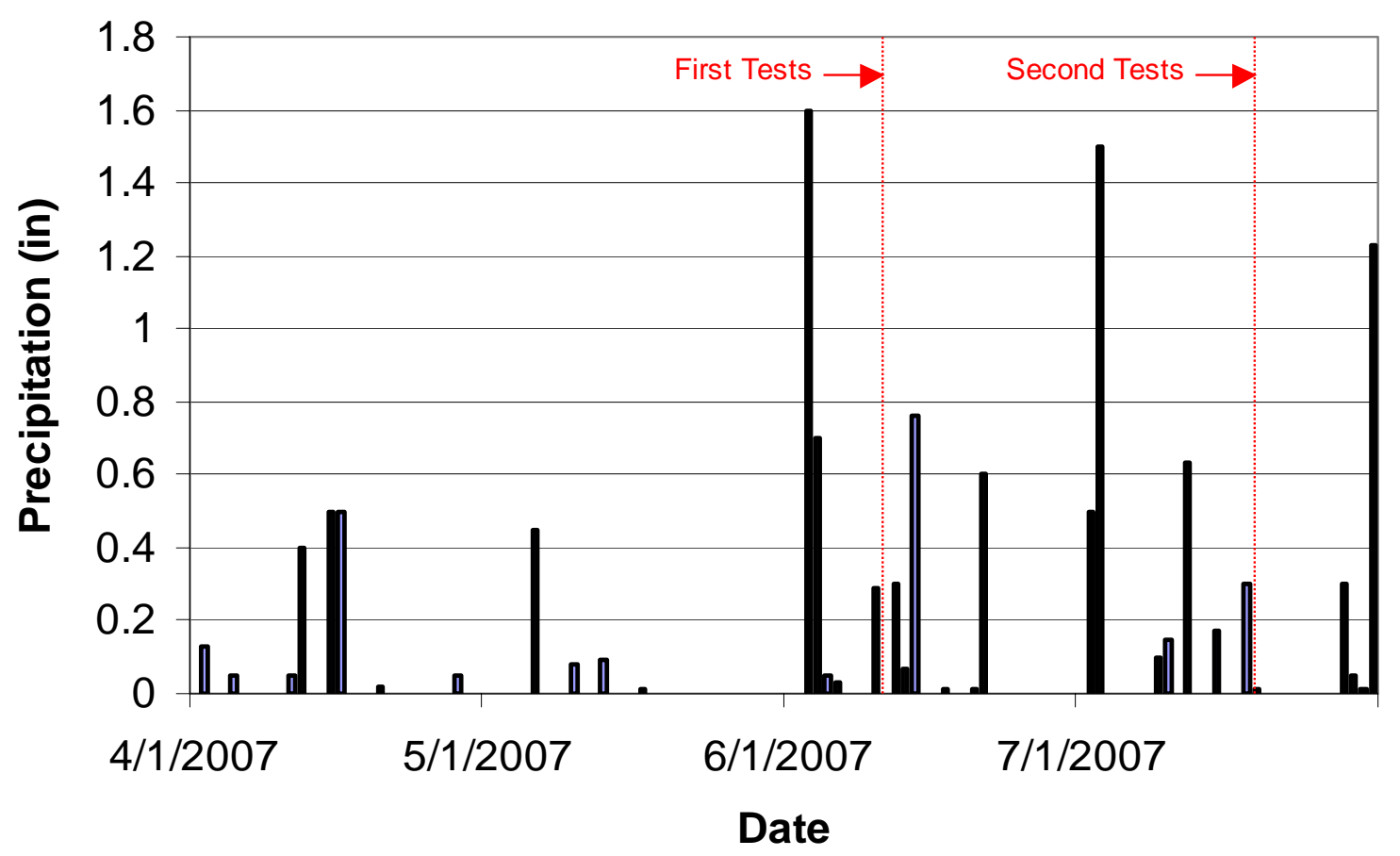

Figure 8- Record of precipitation leading up too, and during well testing period.

Decreasing the relative permeability of the formation within the radius of influence of an SVE well will decrease the mass flow rate. However, applying a vacuum to a well (particularly the extreme vacuums applied during phase 2 testing) will cause pore water to flow towards the well screen and into the casing. If the water is systematically removed from the casing, using solenoid valves on atmospheric valves for instance, then the majority of the water in the formation near the well would be removed in a fairly short period of time. This scenario was investigated using a simple modeling approach. The model involved running an SVE well at constant pressure until an acceptably equilibrated state was reached. At this point the water saturation in the cells within the vicinity of the well screen was increased to 0.3 . This caused an abrupt decrease in flow rate (Figure 9). The flow rate, however, rebounded to near the presaturation value fairly quickly (within 2 days) as the water was pulled toward the well screen and removed from the system (Figure 9). The time that it would take for this process to occur would depend on properties of the formation (this simulation was not calibrated to field conditions in any way), however, if infiltration of water is responsible for decreasing flow rate then the system should rebound eventually. Further evaluation of later field pumping data may be required to conclude whether this will/has happened or not. 


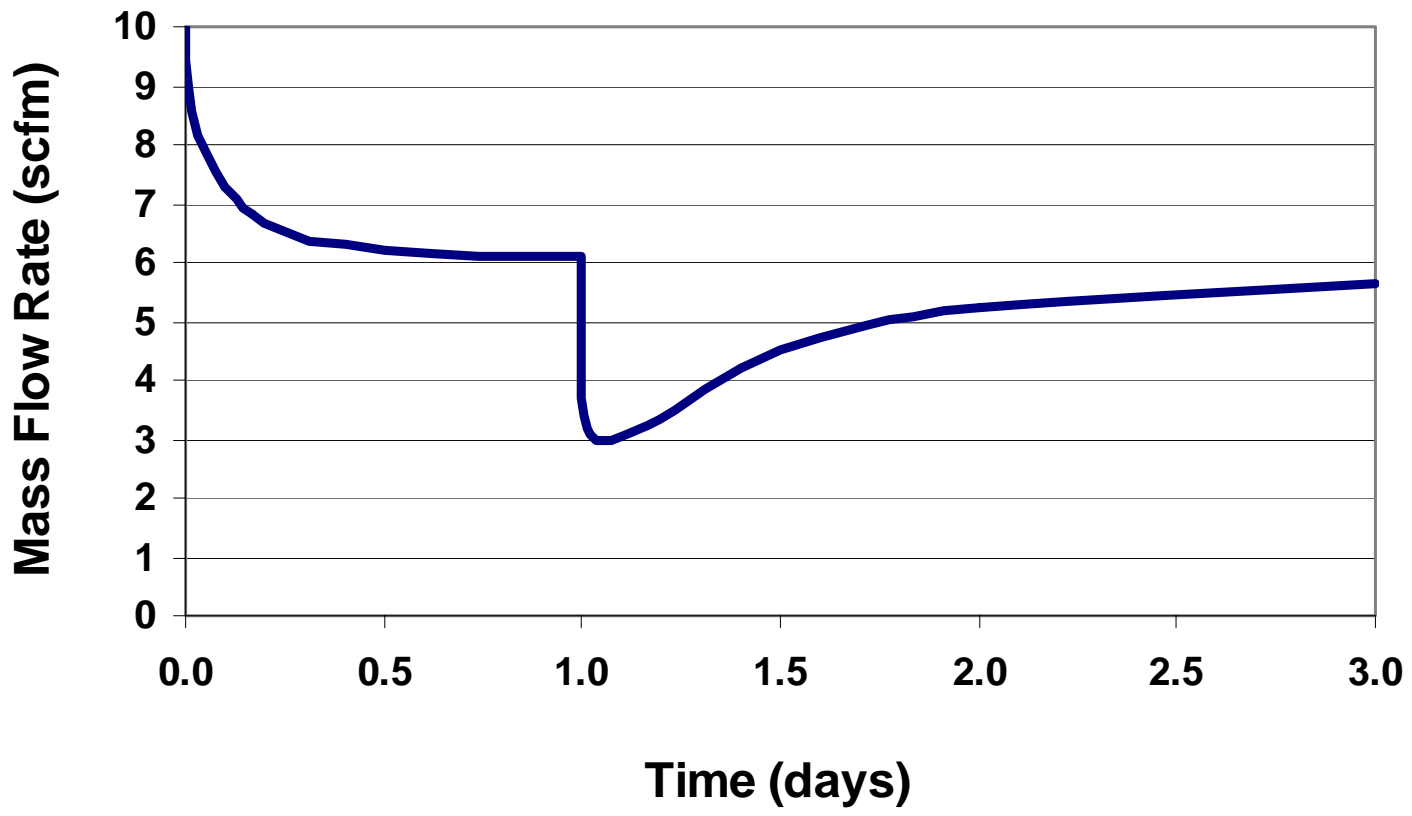

Figure 9- Results from infiltration simulation.

Another explanation for decreases in flow rates may be some change effected on the physical properties (other than saturation alone) of the formation material and/or fracture material. An explanation such as this seems particularly required for the extreme case observed in well AF-5 and the anomalous behavior of well AF-7. A possible scenario that would account for this change is if there was some liquefaction of formation materials during SVE testing. This would not be unlikely given the increased water saturation and abrupt pressure change conditions associated with the rain events and abrupt starts/stops of vacuum on the wells during sampling. If the formation material around the fracture reached high water saturations, which would be likely since the vacuum applied at the well pulls water toward the fracture, then liquefaction could take place. In this instance the liquefied material could flow into and deposit within the fracture sand material. This would permanently decrease the permeability of the hydraulic fracture, thus permanently decreasing the flow rate obtained during SVE operation. Well AF-5 and AF-7 may be more susceptible to this problem due to the fact that they are completed at shallow depths as compared to the other fractured wells. Well AF-5 is also located adjacent to a creek that flows heavily during storm events. What exactly happened to wells AF-5 and 7 cannot be known for sure, however, we know that most of the affect on AF-5 was abrupt (Figure3, following sample event 3). Flow rate and pressure were not logged at a high frequency during the pressure step tests, however, an abrupt decrease in performance of well AF-7 seems to have occurred when the vacuum pressure was increased from 5 to 10 in Hg during phase one testing (Figure 2). These abrupt changes suggest that the problems with these wells are associated with something other than just water infiltration, which would happen over a longer period of time. 


\section{Conclusions}

The results of this study suggest that hydraulically fractured wells tend to perform better (based on flow rate verses pressure) than conventional wells at the A-014 Outfall site. This evidence further supports conclusions drawn during previous work in M-area. The M-area work showed that hydraulically fracturing wells is an effective means of negating problems associated with well skin, which is most likely a major factor effecting flow rates of conventional wells located in A/M-area. The subsurface pressure distribution data observed during testing (not shown) also suggests that the radii of influence of hydraulically fractured wells are for the most part, significantly greater than that of the conventional well tested in this study.

Data collected during this study show that the performance of hydraulically fractured wells may tend to decrease with time/usage under some field conditions. This type of reaction to SVE has been observed in previous work (Murdoch, 1990), where it was attributed to reduction in vapor phase permeability following in flow of water. Of the five hydraulically fractured wells, one was unaffected (well AF-2), two were affected moderately (wells AF-4 and 8), and two were affected to a large extent and/or showed anomalous behavior (wells 5 and 7) (Figure 6). It is possible that the flow rates at A-area could rebound with additional time. However, rebound during previous studies has occurred soon after dewatering the wells, and this was not observed during the A-area study.

\section{References}

Hall, R.H. 2005. Effects of sand-filled hydraulic fractures during air sparging in saprolite. Master's Thesis. Dept. of Geology, Clemson University.

Murdoch, L.C. Increased permeability of soils by hydraulic fracturing--a field test, Proceedings of 21st Ohio River Valley Soils Seminar, October, 26, 1990. 


\section{Appendix B - A-014 Outfall Fracture Enhanced SVE Operational History}

\begin{tabular}{|c|c|}
\hline Date & Operating Description \\
\hline $6 / 11 / 2007$ & $\begin{array}{l}\text { Initial drawdown testing conducted on all } 5 \text { wells at vacuums of } 5 \text {, } \\
10,15 \text { inches } \mathrm{Hg} \text {. }\end{array}$ \\
\hline $6 / 13 / 2007$ & $\begin{array}{l}\text { Re-plumbed solenoid valves - needed to reverse direction to work } \\
\text { with vacuum instead of pressure. }\end{array}$ \\
\hline $6 / 19 / 2007$ & $\begin{array}{l}\text { Started full operation at maximum vacuum with wells AF-2, }-4 \text { and - } \\
5 .\end{array}$ \\
\hline $6 / 22 / 2007$ & $\begin{array}{l}\text { Solenoid failed on water knock-out tanks and could not be closed to } \\
\text { maintain vacuum and flow on the wells. Ordered new valve. }\end{array}$ \\
\hline $6 / 28 / 2007$ & $\begin{array}{l}\text { Reinstalled valve and restarted system at maximum vacuum with } \\
\text { wells AF-2, }-4 \text { and }-5 \text {. }\end{array}$ \\
\hline $7 / 9 / 2007$ & Changed wells to AF-7 and -8 with maximum vacuum. \\
\hline $7 / 17 / 2007$ & $\begin{array}{l}\text { Shutdown test SVE system and SVE unit } 4 \mathrm{M} \text { on } 7 / 16 / 07 \text { and ran } \\
\text { drawdown tests on each well at vacuums of } 5,10 \text { and } 15 \text { inches } \mathrm{Hg} \text {. } \\
\text { Restarted test system at maximum vacuum with wells AF-2, }-4 \text {, and - } \\
8 \text {. }\end{array}$ \\
\hline $7 / 26 / 2007$ & $\begin{array}{l}\text { Reconstructed duel phase removal well heads for AF-5 and -7. SVE } \\
\text { test Unit oil level was low so the system was shutdown. }\end{array}$ \\
\hline $7 / 27 / 2007$ & $\begin{array}{l}\text { Fixed oil problem and refilled unit. Changed wells to AF-5 and -7 } \\
\text { and operated at maximum vacuum. High vacuum and low flow } \\
\text { rates, but water is being removed. }\end{array}$ \\
\hline $8 / 10 / 2007$ & $\begin{array}{l}\text { Changed wells to AF-2 and }-4 \text { with maximum vacuum to maximize } \\
\text { mass removal. }\end{array}$ \\
\hline $8 / 14 / 2007$ & $\begin{array}{l}\text { Oil was being consumed. Shutdown at 10:48 and checked system } \\
\text { over. Restarted at 16:00 }\end{array}$ \\
\hline $8 / 21 / 2007$ & $\begin{array}{l}\text { Oil was being consumed and misting from the stack was occurring. } \\
\text { Shutdown at 17:15. Ordered Oil. }\end{array}$ \\
\hline $8 / 27 / 2007$ & Performed maintenance and refilled oil. Restarted at 15:30 \\
\hline 9/11/2007 & $\begin{array}{l}\text { Oil problems still occurring. Shutdown system at 8:50. Found a } \\
\text { blocked oil return line and cleared it. Restarted at 12:00. }\end{array}$ \\
\hline $10 / 24 / 2007$ & Area wide power outage caused unit to shutdown at $\sim 15: 00$. \\
\hline $10 / 25 / 2007$ & $\begin{array}{l}\text { The high vacuum from the wells caused the oil to move backward in } \\
\text { the system and fill and saturate the inlet air filter. Cleaned out and } \\
\text { restarted. Some rough bearing noises were heard. }\end{array}$ \\
\hline $11 / 12 / 2007$ & $\begin{array}{l}\text { Minor oil leak was occurring. Loose bolts were found on the } \\
\text { transfer unit connecting the motor and pump. These were tightened } \\
\text { and the leak was stopped. This was likely a result of the abrupt } \\
\text { shutdown during the power outage. The unit should not be shutdown } \\
\text { under maximum vacuum. This also corrected the noises and } \\
\text { vibrations that were reported. }\end{array}$ \\
\hline $12 / 2 / 2007$ & $\begin{array}{l}\text { The unit went down about 3:00 AM on Sunday morning. The drive } \\
\text { shaft between motor and the pump has failed. The motor will run } \\
\text { but the pump is not turning and noise can be heard in the connection } \\
\text { between the pump and motor. It could be related to the abrupt } \\
\text { shutdown during the power outage on } 10 / 24 / 07 \text {. }\end{array}$ \\
\hline
\end{tabular}




\section{Appendix C - A-014 Outfall Fracture Enhanced SVE Analytical and Operational Data}

This appendix contains data collected from the SVE unit (stack sample) and from individual fracture wells. Table C-1 provides the high vacuum SVE unit data including IRPAS (infra-red photo-acoustic spectrometer) concentration data for PCE, TCE and $\mathrm{CO}_{2}$, vacuum as measured from a mechanical gauge on the unit, flow rate in scfm (standard $\mathrm{ft}^{3} / \mathrm{min}$ ) as measured from a Kurz digital mass flow meter, PCE mass removal rate in lbs/day based on the point flow and concentration data and the wells connected to the SVE unit during those measurements. In the tables, 'nm' indicates the parameter was not measured or recorded.

Tables C-2 through C-6 provide IRPAS concentration, vacuum and flow data for wells AF-2, AF-4, AF-5, AF-7 and AF-8 respectively. These data were collected by isolating individual wells and collecting samples and measurements at the SVE unit. Data recorded from 9/27/07 to 11/13/07 on individual wells AF-2 and AF-4 are suspect and it appears the wells were not completely isolated during the sampling. Figures C-1 through C-5 provide plots of concentration, flow and vacuum for wells AF-2, AF-4, AF-5, AF7 and AF-8 respectively.

Table C-7 provides gas chromatography (GC) data results from selected stack samples. The GC method used was Savannah River National Laboratory’s modified Method 18 for gas analyses. IRPAS and GC results were compared to determine the precision of the IRPAS instrument since it is considered a screening analysis. IRPAS and GC data were in fairly good agreement; however results were approximately 7\% low for PCE and 8\% low for TCE on the IRPAS instrument. Except for the lower readings of the IRPAS instrument, the correlation between the two analysis methods was good and considered within the error range of the sampling and analysis methods. The IRPAS and GC comparison plots are provided in Figures C-6 and C-7. The total mass removal calculations were based on the IRPAS data that was corrected by $7 \%$ for PCE and $8 \%$ for TCE since more IRPAS data was collected and provided for more accurate tracking of concentration changes.

Table C-1 - Concentration and Operation Data for SVE Unit

\begin{tabular}{|c|c|c|c|c|c|c|c|}
\hline Sample Date Time & $\begin{array}{l}\text { PCE, } \\
\text { ppmv }\end{array}$ & $\begin{array}{l}\text { TCE, } \\
\text { ppmv }\end{array}$ & $\begin{array}{l}\mathrm{CO}_{2}, \\
\text { ppmv }\end{array}$ & $\begin{array}{c}\text { Vacuum, } \\
\text { in } \mathrm{Hg}\end{array}$ & $\begin{array}{l}\text { Flow } \\
\text { Rate } \\
\text { scfm }\end{array}$ & $\begin{array}{l}\text { PCE, } \\
\text { lbs/day }\end{array}$ & $\begin{array}{c}\text { Wells } \\
\text { Connected }\end{array}$ \\
\hline 6/9/07 11:30 & 759 & 4.5 & 2800 & 15.0 & 88.7 & 41.0 & $\mathrm{AF}-2,4,5$ \\
\hline 6/9/07 16:15 & 867 & 11.2 & 3010 & 16.0 & 86.0 & 45.4 & $\mathrm{AF}-2,4,5$ \\
\hline 6/12/07 16:00 & 888 & 12.3 & 3150 & 18.0 & 71.8 & 38.8 & $\mathrm{AF}-2,4,5$ \\
\hline 6/13/07 14:20 & 949 & 11.8 & 3400 & 17.5 & 79.0 & 45.7 & AF-2, 4, 5 \\
\hline 6/19/07 14:30 & 955 & 13.9 & 3600 & 19.5 & 61.3 & 35.7 & $\mathrm{AF}-2,4,5$ \\
\hline 6/20/07 10:40 & 782 & 12.6 & 3650 & 20.0 & 58.1 & 27.7 & $\mathrm{AF}-2,4,5$ \\
\hline 6/20/07 16:40 & $\mathrm{nm}$ & $\mathrm{nm}$ & $\mathrm{nm}$ & 19.8 & 59.7 & $\mathrm{~nm}$ & AF- $2,4,5$ \\
\hline 6/21/07 9:30 & 928 & 8.7 & 3740 & 22.0 & 44.2 & 25.0 & $\mathrm{AF}-2,4,5$ \\
\hline 6/22/07 8:15 & 940 & 9.5 & 3780 & 22.0 & 42.5 & 24.3 & $\mathrm{AF}-2,4,5$ \\
\hline $6 / 28 / 07$ 14:33 & $\mathrm{nm}$ & $\mathrm{nm}$ & $\mathrm{nm}$ & 20.0 & 66.5 & $\mathrm{~nm}$ & $\mathrm{AF}-2,4,5$ \\
\hline 6/29/07 8:00 & 880 & 12.7 & 3880 & 21.0 & 56.3 & 30.2 & $\mathrm{AF}-2,4,5$ \\
\hline $6 / 29 / 07$ 14:25 & $\mathrm{nm}$ & $\mathrm{nm}$ & $\mathrm{nm}$ & 21.0 & 48.3 & $\mathrm{~nm}$ & $\mathrm{AF}-2,4,5$ \\
\hline 7/2/07 10:30 & $\mathrm{nm}$ & $\mathrm{nm}$ & $\mathrm{nm}$ & 22.0 & 42.7 & $\mathrm{~nm}$ & $\mathrm{AF}-2,4,5$ \\
\hline 7/2/07 10:30 & $\mathrm{nm}$ & $\mathrm{nm}$ & $\mathrm{nm}$ & 22.0 & 42.7 & $\mathrm{~nm}$ & $\mathrm{AF}-2,4,5$ \\
\hline $7 / 2 / 07$ 16:56 & $\mathrm{nm}$ & $\mathrm{nm}$ & $\mathrm{nm}$ & 23.0 & 37.0 & $\mathrm{~nm}$ & $\mathrm{AF}-2,4,5$ \\
\hline 7/3/07 9:30 & 931 & 12.5 & 4020 & 23.0 & 37.8 & 21.4 & $\mathrm{AF}-2,4,5$ \\
\hline 7/3/07 18:00 & $\mathrm{nm}$ & $\mathrm{nm}$ & $\mathrm{nm}$ & 23.0 & 38.2 & $\mathrm{~nm}$ & AF-2, 4, 5 \\
\hline 7/5/07 8:30 & 879 & 12.8 & 3960 & 23.0 & 37.9 & 20.3 & $\mathrm{AF}-2,4,5$ \\
\hline
\end{tabular}


Table C-1 - Concentration and Operation Data for SVE Unit

\begin{tabular}{|c|c|c|c|c|c|c|c|}
\hline Sample Date Time & $\begin{array}{l}\text { PCE, } \\
\text { ppmv }\end{array}$ & $\begin{array}{l}\text { TCE, } \\
\text { ppmv }\end{array}$ & $\begin{array}{l}\mathrm{CO}_{2}, \\
\mathrm{ppmv}\end{array}$ & $\begin{array}{c}\text { Vacuum, } \\
\text { in Hg }\end{array}$ & $\begin{array}{l}\text { Flow } \\
\text { Rate } \\
\text { scfm }\end{array}$ & $\begin{array}{c}\text { PCE, } \\
\text { lbs/day }\end{array}$ & $\begin{array}{c}\text { Wells } \\
\text { Connected }\end{array}$ \\
\hline 7/5/07 16:20 & $\mathrm{nm}$ & $\mathrm{nm}$ & $\mathrm{nm}$ & 23.0 & 37.7 & $\mathrm{~nm}$ & $\mathrm{AF}-2,4,5$ \\
\hline 7/6/07 14:10 & 842 & 12.4 & 4020 & 23.0 & 37.8 & 19.4 & $\mathrm{AF}-2,4,5$ \\
\hline 7/9/07 10:20 & 830 & 14.5 & 4180 & 22.5 & 37.8 & 19.1 & $\mathrm{AF}-2,4,5$ \\
\hline 7/9/07 16:32 & $\mathrm{nm}$ & $\mathrm{nm}$ & $\mathrm{nm}$ & 18.0 & 74.8 & $\mathrm{~nm}$ & AF-7, 8 \\
\hline 7/10/07 9:30 & 140 & 6.1 & 4170 & 18.0 & 73.5 & 6.3 & AF-7, 8 \\
\hline 7/11/07 9:30 & 205 & 5.8 & 4400 & 18.0 & 73.3 & 9.2 & AF-7, 8 \\
\hline 7/12/07 10:32 & 198 & 3.9 & 4450 & 18.0 & 71.0 & 8.6 & AF-7, 8 \\
\hline 7/12/07 10:45 & 203 & 4.0 & 4590 & 18.5 & 67.4 & 8.3 & $\mathrm{AF}-7,8$ \\
\hline 7/16/07 11:30 & 194 & 4.6 & 4220 & 20.0 & $\mathrm{~nm}$ & $\mathrm{~nm}$ & AF-7, 8 \\
\hline 7/18/07 10:15 & 441 & 6.8 & 4830 & 18.0 & 73.8 & 19.8 & $\mathrm{AF}-2,4,8$ \\
\hline 7/19/07 9:30 & 413 & 10.0 & 4890 & 18.0 & 72.0 & 18.1 & $\mathrm{AF}-2,4,8$ \\
\hline 7/23/07 10:30 & 382 & 6.7 & 4830 & 19.0 & 72.4 & 16.9 & $\mathrm{AF}-2,4,8$ \\
\hline 7/24/07 9:45 & 375 & 6.5 & 4690 & 19.0 & 71.6 & 16.4 & $\mathrm{AF}-2,4,8$ \\
\hline 7/25/07 10:15 & 412 & 7.3 & 5030 & 19.0 & 71.2 & 17.9 & $\mathrm{AF}-2,4,8$ \\
\hline 7/27/07 15:50 & 182 & 3.9 & 5000 & 26.0 & 8.0 & 0.9 & AF-5, 7 \\
\hline 7/30/07 9:15 & 370 & 6.3 & 4570 & 25.0 & 9.7 & 2.2 & AF-5, 7 \\
\hline 7/31/07 9:40 & 385 & 6.0 & 4370 & 25.5 & 5.2 & 1.2 & AF-5, 7 \\
\hline 8/1/07 9:25 & 320 & 5.3 & 4240 & 26.0 & 4.4 & 0.9 & AF-5, 7 \\
\hline 8/2/07 9:45 & 329 & 2.2 & 4290 & 26.0 & 4.8 & 1.0 & AF-5, 7 \\
\hline 8/6/07 13:45 & 395 & 8.1 & 4470 & 26.0 & 5.7 & 1.4 & AF-5, 7 \\
\hline 8/7/07 9:45 & 375 & 7.6 & 4500 & 26.0 & 5.6 & 1.3 & AF-5, 7 \\
\hline 8/8/07 9:30 & 393 & 7.8 & 4610 & 26.0 & 5.8 & 1.4 & AF-5, 7 \\
\hline 8/9/07 9:30 & 322 & 6.8 & 4180 & 26.0 & 6.8 & 1.3 & $\mathrm{AF}-5,7$ \\
\hline 8/15/07 11:25 & 867 & 18.4 & 5510 & 23.0 & 34.1 & 18.0 & AF-2, 4 \\
\hline 8/16/07 8:24 & 898 & 17.7 & 5350 & 23.0 & 34.5 & 18.9 & AF-2, 4 \\
\hline 8/20/07 8:41 & 843 & 18.0 & 5260 & 23.0 & 34.2 & 17.6 & AF-2, 4 \\
\hline 8/28/07 10:56 & 796 & 17.2 & 5840 & 23.0 & 38.6 & 18.7 & $\mathrm{AF}-2,4$ \\
\hline 8/29/07 9:55 & 716 & 17.3 & 5290 & 23.0 & 37.7 & 16.4 & $\mathrm{AF}-2,4$ \\
\hline 8/30/07 8:16 & 770 & 17.1 & 5210 & 23.0 & 36.9 & 17.3 & AF-2, 4 \\
\hline 9/6/07 9:34 & 752 & 18.5 & 5450 & 23.0 & 36.1 & 16.5 & AF-2, 4 \\
\hline 9/7/07 7:52 & 751 & 18.6 & 5410 & 23.0 & 35.1 & 16.1 & AF-2, 4 \\
\hline 9/10/07 8:03 & 776 & 19.6 & 5400 & 23.0 & 35.6 & 16.8 & AF-2, 4 \\
\hline 9/11/07 8:15 & 776 & 19.4 & 5360 & 23.0 & 35.5 & 16.8 & AF-2, 4 \\
\hline 9/12/07 8:42 & 789 & 19.9 & 5370 & 23.0 & 35.9 & 17.3 & $\mathrm{AF}-2,4$ \\
\hline 9/13/07 8:14 & 788 & 19.9 & 5480 & 23.0 & 35.0 & 16.8 & AF-2, 4 \\
\hline 9/17/07 10:01 & 727 & 19.2 & 5650 & 23.0 & 33.8 & 15.0 & AF-2, 4 \\
\hline 9/18/07 8:46 & 711 & 18.4 & 5580 & 23.0 & 33.6 & 14.6 & AF-2, 4 \\
\hline 9/19/07 8:38 & 725 & 18.7 & 5690 & 23.0 & 33.5 & 14.8 & $\mathrm{AF}-2,4$ \\
\hline 9/20/07 7:48 & 702 & 18.2 & 5500 & 23.0 & 33.6 & 14.4 & $\mathrm{AF}-2,4$ \\
\hline 9/21/07 7:57 & 708 & 18.4 & 5650 & 23.0 & 33.2 & 14.3 & AF-2, 4 \\
\hline 9/24/07 7:51 & 712 & 17.8 & 5650 & 23.0 & 32.4 & 14.1 & AF-2, 4 \\
\hline 9/25/07 7:58 & 728 & 18.0 & 5730 & 23.0 & 32.2 & 14.3 & $\mathrm{AF}-2,4$ \\
\hline 9/26/07 9:05 & 740 & 18.5 & 5760 & 23.0 & 32.3 & 14.6 & $\mathrm{AF}-2,4$ \\
\hline 9/27/07 9:17 & 743 & 18.7 & 5790 & 23.0 & 32.2 & 14.6 & AF-2, 4 \\
\hline 10/1/07 8:33 & 772 & 19.3 & 5770 & 23.5 & 32.6 & 15.3 & AF-2, 4 \\
\hline
\end{tabular}


Table C-1 - Concentration and Operation Data for SVE Unit

\begin{tabular}{|c|c|c|c|c|c|c|c|}
\hline Sample Date Time & $\begin{array}{l}\text { PCE, } \\
\text { ppmv }\end{array}$ & $\begin{array}{l}\text { TCE, } \\
\text { ppmv }\end{array}$ & $\begin{array}{l}\mathrm{CO}_{2}, \\
\text { ppmv }\end{array}$ & $\begin{array}{l}\text { Vacuum, } \\
\text { in } \mathrm{Hg}\end{array}$ & $\begin{array}{l}\text { Flow } \\
\text { Rate } \\
\text { scfm }\end{array}$ & $\begin{array}{l}\text { PCE, } \\
\text { lbs/day }\end{array}$ & $\begin{array}{c}\text { Wells } \\
\text { Connected } \\
\end{array}$ \\
\hline 10/2/07 8:39 & 813 & 20.3 & 5910 & 23.5 & 32.4 & 16.0 & $\mathrm{AF}-2,4$ \\
\hline 10/3/07 8:16 & 799 & 20.5 & 5810 & 23.0 & 32.6 & 15.9 & AF-2, 4 \\
\hline 10/4/07 8:53 & 821 & 21.4 & 5810 & 23.0 & 32.8 & 16.4 & AF-2, 4 \\
\hline 10/5/07 8:40 & 831 & 21.6 & 5820 & 23.0 & 32.3 & 16.4 & AF-2, 4 \\
\hline 10/8/07 8:52 & 837 & 21.5 & 5890 & 23.5 & 32.0 & 16.3 & AF-2, 4 \\
\hline 10/9/07 8:41 & 842 & 21.6 & 5860 & 23.5 & 32.1 & 16.5 & AF-2, 4 \\
\hline 10/10/07 8:23 & 839 & 21.5 & 5850 & 23.0 & 31.8 & 16.3 & AF-2, 4 \\
\hline 10/11/07 8:47 & 859 & 22.0 & 5890 & 23.0 & 31.6 & 16.5 & AF-2, 4 \\
\hline 10/15/07 8:32 & 874 & 23.1 & 6090 & 23.5 & 31.6 & 16.8 & AF-2, 4 \\
\hline 10/16/07 8:38 & 884 & 23.7 & 6140 & 23.5 & 31.9 & 17.2 & AF-2, 4 \\
\hline 10/17/07 7:57 & 885 & 23.8 & 6030 & 23.0 & 31.9 & 17.2 & AF-2, 4 \\
\hline 10/18/07 8:17 & 881 & 24.3 & 5990 & 23.0 & 31.8 & 17.1 & AF-2, 4 \\
\hline 10/19/07 7:59 & 904 & 24.8 & 5990 & 23.0 & 32.8 & 18.1 & AF-2, 4 \\
\hline 10/22/07 8:55 & 909 & 25.0 & 6010 & 23.5 & 32.9 & 18.2 & AF-2, 4 \\
\hline 10/23/07 8:03 & 918 & 25.5 & 6070 & 23.0 & 32.8 & 18.3 & AF-2, 4 \\
\hline 10/29/07 9:57 & 849 & 23.2 & 6120 & 23.5 & 33.6 & 17.4 & AF-2, 4 \\
\hline 10/30/07 10:51 & 837 & 22.5 & 6130 & 24.0 & 30.9 & 15.8 & AF-2, 4 \\
\hline 10/31/07 9:00 & 833 & 22.2 & 6170 & 24.0 & 31.3 & 15.9 & AF-2, 4 \\
\hline 11/1/07 8:21 & 828 & 22.0 & 6160 & 24.0 & 31.0 & 15.6 & AF-2, 4 \\
\hline 11/2/07 9:57 & 821 & 21.8 & 6160 & 23.5 & 32.0 & 16.0 & AF-2, 4 \\
\hline 11/5/07 8:35 & 821 & 21.2 & 6120 & 23.5 & 31.3 & 15.7 & AF-2, 4 \\
\hline 11/6/07 8:03 & 819 & 21.4 & 6100 & 23.5 & 31.6 & 15.8 & AF-2, 4 \\
\hline 11/7/07 14:06 & 831 & 21.7 & 6130 & 23.5 & 31.4 & 15.9 & AF-2, 4 \\
\hline 11/8/07 8:09 & $\mathrm{nm}$ & $\mathrm{nm}$ & $\mathrm{nm}$ & 23.5 & 31.2 & $\mathrm{~nm}$ & AF-2, 4 \\
\hline 11/12/07 10:33 & 824 & 22.8 & 6080 & 23.5 & 30.8 & 15.5 & AF-2, 4 \\
\hline 11/13/07 8:24 & 842 & 22.5 & 6050 & 23.5 & 31.1 & 16.0 & AF-2, 4 \\
\hline 11/14/07 8:29 & 852 & 23.2 & 6080 & 23.5 & 31.3 & 16.2 & AF-2, 4 \\
\hline 11/15/07 9:15 & 857 & 23.5 & 6100 & 23.0 & 31.4 & 16.4 & AF-2, 4 \\
\hline 11/16/07 9:11 & 867 & 23.4 & 6050 & 23.0 & 31.0 & 16.4 & AF-2, 4 \\
\hline 11/19/07 10:12 & 821 & 25.3 & 6060 & 23.0 & 30.9 & 15.4 & AF-2, 4 \\
\hline 11/20/07 8:18 & 853 & 25.6 & 6110 & 23.0 & 31.2 & 16.2 & AF-2, 4 \\
\hline 11/26/07 10:11 & 836 & 24.2 & 6000 & 23.0 & 31.3 & 15.9 & AF-2, 4 \\
\hline 11/27/07 8:47 & 844 & 24.3 & 6060 & 23.5 & 31.6 & 16.3 & AF-2, 4 \\
\hline 11/28/07 9:17 & 856 & 24.3 & 6070 & 23.5 & 31.0 & 16.2 & AF-2, 4 \\
\hline 11/29/07 8:34 & 845 & 23.8 & 6080 & 23.5 & 31.6 & 16.3 & AF-2, 4 \\
\hline 11/30/07 9:25 & 833 & 23.5 & 6070 & 23.5 & 30.5 & 15.5 & AF-2, 4 \\
\hline
\end{tabular}


Table C-2 - Concentration and Operation Data for Well AF-2

\begin{tabular}{|c|c|c|c|c|c|}
\hline $\begin{array}{c}\text { Sample Date and } \\
\text { Time }\end{array}$ & $\begin{array}{l}\text { PCE, } \\
\text { ppmv }\end{array}$ & $\begin{array}{l}\text { TCE, } \\
\text { ppmv }\end{array}$ & $\begin{array}{l}\mathrm{CO}_{2}, \\
\text { ppmv }\end{array}$ & $\begin{array}{l}\text { Vacuum, } \\
\text { in } \mathrm{Hg}\end{array}$ & $\begin{array}{l}\text { Flow } \\
\text { Rate, } \\
\text { scfm }\end{array}$ \\
\hline 6/9/07 16:15 & 1280 & 7.8 & 2500 & $\mathrm{~nm}$ & $\mathrm{~nm}$ \\
\hline 6/12/07 16:02 & 1230 & 8.0 & 2840 & $\mathrm{~nm}$ & $\mathrm{~nm}$ \\
\hline 6/13/07 14:22 & 1250 & 9.0 & 3430 & $\mathrm{~nm}$ & $\mathrm{~nm}$ \\
\hline 6/19/07 14:32 & 1240 & 8.7 & 3470 & 23.0 & 32.1 \\
\hline $6 / 20 / 07$ 10:40 & 1130 & 8.5 & 3660 & 23.0 & 29.5 \\
\hline $6 / 20 / 07$ 16:40 & $\mathrm{nm}$ & $\mathrm{nm}$ & $\mathrm{nm}$ & 23.5 & 28.7 \\
\hline 6/21/07 9:32 & 1030 & 9.1 & 3730 & 23.5 & 29.1 \\
\hline 6/22/07 8:17 & 1010 & 9.4 & 3790 & 23.5 & 29.0 \\
\hline 6/28/07 14:33 & $\mathrm{nm}$ & $\mathrm{nm}$ & $\mathrm{nm}$ & 23.5 & 33.3 \\
\hline 6/29/07 8:02 & 1140 & 13.0 & 3690 & 23.0 & 31.0 \\
\hline $6 / 29 / 07$ 14:25 & $\mathrm{nm}$ & $\mathrm{nm}$ & $\mathrm{nm}$ & 23.0 & 29.5 \\
\hline $7 / 2 / 07$ 10:30 & $\mathrm{nm}$ & $\mathrm{nm}$ & $\mathrm{nm}$ & 24.0 & 24.5 \\
\hline $7 / 2 / 07$ 10:30 & $\mathrm{nm}$ & $\mathrm{nm}$ & $\mathrm{nm}$ & 24.0 & 24.5 \\
\hline 7/2/07 16:56 & $\mathrm{nm}$ & $\mathrm{nm}$ & $\mathrm{nm}$ & 25.0 & 25.4 \\
\hline 7/3/07 9:32 & 1090 & 16.8 & 3860 & 24.0 & 25.3 \\
\hline $7 / 3 / 07$ 18:00 & $\mathrm{nm}$ & $\mathrm{nm}$ & $\mathrm{nm}$ & 24.0 & 25.0 \\
\hline 7/5/07 8:32 & 1070 & 17.8 & 3930 & 24.0 & 26.1 \\
\hline 7/5/07 16:20 & $\mathrm{nm}$ & $\mathrm{nm}$ & $\mathrm{nm}$ & 24.0 & 26.2 \\
\hline 7/9/07 10:22 & 1010 & 20.8 & 4070 & 24.0 & 26.2 \\
\hline 8/15/07 11:20 & 1010 & 26.4 & 4960 & 24.0 & 22.6 \\
\hline 8/16/07 8:55 & 1040 & 22.2 & 4740 & 24.0 & 22.7 \\
\hline 8/20/07 8:58 & 969 & 22.2 & 4850 & 24.5 & 22.8 \\
\hline 8/28/07 11:13 & 944 & 20.5 & 5300 & 24.0 & 26.2 \\
\hline 8/29/07 10:12 & 847 & 22.3 & 5010 & 24.0 & 28.8 \\
\hline 8/30/07 8:35 & 874 & 20.0 & 4850 & 24.0 & 27.8 \\
\hline 9/6/07 9:58 & 899 & 20.1 & 5120 & 24.0 & 27.2 \\
\hline 9/7/07 8:12 & 871 & 22.2 & 5140 & 24.0 & 27.8 \\
\hline 9/10/07 8:28 & 907 & 22.7 & 5130 & 24.0 & 27.1 \\
\hline 9/11/07 8:33 & 901 & 21.4 & 5080 & 24.0 & 27.0 \\
\hline 9/12/07 8:55 & 920 & 23.7 & 5170 & 24.0 & 27.6 \\
\hline 9/13/07 8:32 & 888 & 22.5 & 5200 & 24.0 & 26.7 \\
\hline 9/17/07 10:15 & 832 & 22.0 & 5440 & 24.0 & 24.9 \\
\hline 9/18/07 9:02 & 831 & 22.7 & 5480 & 24.0 & 25.2 \\
\hline 9/19/07 8:53 & 825 & 21.6 & 5490 & 24.0 & 25.5 \\
\hline 9/20/07 8:05 & 831 & 22.7 & 5510 & 24.0 & 25.3 \\
\hline 9/21/07 8:16 & 833 & 22.4 & 5530 & 24.0 & 24.5 \\
\hline 9/24/07 8:10 & 821 & 21.3 & 5510 & 24.0 & 25.2 \\
\hline 9/25/07 8:15 & 864 & 23.9 & 5620 & 24.0 & 24.4 \\
\hline 9/26/07 9:21 & 867 & 23.7 & 5580 & 24.0 & 23.8 \\
\hline 9/27/07 9:29* & 765 & 19.7 & 5720 & 23.5 & 30.5 \\
\hline 10/1/07 8:44* & 885 & 25.0 & 5770 & 24.0 & 26.2 \\
\hline 10/2/07 8:50* & 852 & 22.5 & 5820 & 24.0 & 28.9 \\
\hline 10/3/07 8:27* & 855 & 22.5 & 5790 & 23.5 & 29.8 \\
\hline 10/4/07 9:06* & 864 & 22.1 & 5770 & 23.5 & 31.1 \\
\hline
\end{tabular}


Table C-2 - Concentration and Operation Data for Well AF-2

\begin{tabular}{|c|c|c|c|c|c|}
\hline $\begin{array}{c}\text { Sample Date and } \\
\text { Time }\end{array}$ & $\begin{array}{l}\text { PCE, } \\
\text { ppmv }\end{array}$ & $\begin{array}{l}\text { TCE, } \\
\text { ppmv }\end{array}$ & $\begin{array}{l}\mathrm{CO}_{2}, \\
\mathrm{ppmv}\end{array}$ & $\begin{array}{l}\text { Vacuum, } \\
\text { in } \mathrm{Hg} \\
\end{array}$ & $\begin{array}{l}\text { Flow } \\
\text { Rate, } \\
\text { scfm }\end{array}$ \\
\hline 10/5/07 8:53* & 867 & 22.7 & 5800 & 23.5 & 30.3 \\
\hline 10/8/07 9:05* & 872 & 22.9 & 5830 & 23.5 & 30.1 \\
\hline 10/9/07 8:50* & 868 & 22.4 & 5880 & 23.5 & 31.0 \\
\hline 10/10/07 8:32* & 861 & 22.1 & 5880 & 23.0 & 30.9 \\
\hline 10/11/07 8:59* & 886 & 22.7 & 5960 & 23.0 & 30.7 \\
\hline 10/15/07 8:44* & 893 & 23.7 & 6100 & 23.5 & 31.2 \\
\hline 10/16/07 8:50* & 894 & 23.7 & 6120 & 23.5 & 31.3 \\
\hline 10/17/07 8:05* & 904 & 24.5 & 6090 & 23.5 & 31.0 \\
\hline 10/18/07 8:25* & 897 & 24.6 & 6010 & 23.0 & 31.4 \\
\hline 10/19/07 8:10* & 912 & 25.2 & 5970 & 23.0 & 32.3 \\
\hline 10/22/07 9:06* & 925 & 25.4 & 6040 & 23.5 & 32.6 \\
\hline 10/23/07 8:11* & 935 & 26.4 & 6050 & 23.5 & 32.1 \\
\hline 10/29/07 10:17* & 905 & 25.4 & 6220 & 24.0 & 31.0 \\
\hline 10/30/07 11:01* & 855 & 23.4 & 6160 & 24.0 & 30.0 \\
\hline 10/31/07 9:11* & 843 & 22.6 & 6150 & 24.0 & 30.3 \\
\hline 11/1/07 8:32* & 841 & 22.6 & 6110 & 24.0 & 30.0 \\
\hline 11/2/07 10:08* & 844 & 22.7 & 6210 & 24.0 & 30.5 \\
\hline 11/5/07 8:49* & 830 & 21.7 & 6090 & 24.0 & 30.8 \\
\hline 11/6/07 8:14* & 832 & 22.1 & 6100 & 23.5 & 30.4 \\
\hline 11/7/07 14:17* & 941 & 29.3 & 6350 & 24.0 & 23.3 \\
\hline 11/8/07 8:20* & 810 & 22.6 & 5420 & 24.0 & 23.2 \\
\hline 11/12/07 10:46* & 836 & 23.5 & 6040 & 24.0 & 30.3 \\
\hline 11/13/07 8:35* & 853 & 22.8 & 6040 & 23.5 & 30.7 \\
\hline 11/14/07 8:46 & 968 & 30.4 & 6390 & 24.0 & 23.4 \\
\hline 11/15/07 9:29 & 972 & 30.8 & 6450 & 24.0 & 23.5 \\
\hline 11/16/07 9:29 & 987 & 31.5 & 6450 & 24.0 & 23.0 \\
\hline 11/19/07 10:24 & 908 & 32.1 & 6310 & 24.0 & 22.8 \\
\hline 11/20/07 8:36 & 986 & 35.9 & 6630 & 24.0 & 23.2 \\
\hline 11/26/07 10:27 & 969 & 32.8 & 6590 & 24.0 & 23.4 \\
\hline 11/27/07 9:15 & 966 & 33.2 & 6750 & 24.0 & 24.0 \\
\hline 11/28/07 9:30 & 962 & 32.0 & 6570 & 24.0 & 23.1 \\
\hline 11/29/07 8:47 & 944 & 31.6 & 6610 & 24.0 & 23.4 \\
\hline 11/30/07 9:42 & 943 & 31.4 & 6720 & 24.0 & 22.5 \\
\hline
\end{tabular}

* Data is suspect. Valve on AF-4 was likely not closed all the way during sampling. 

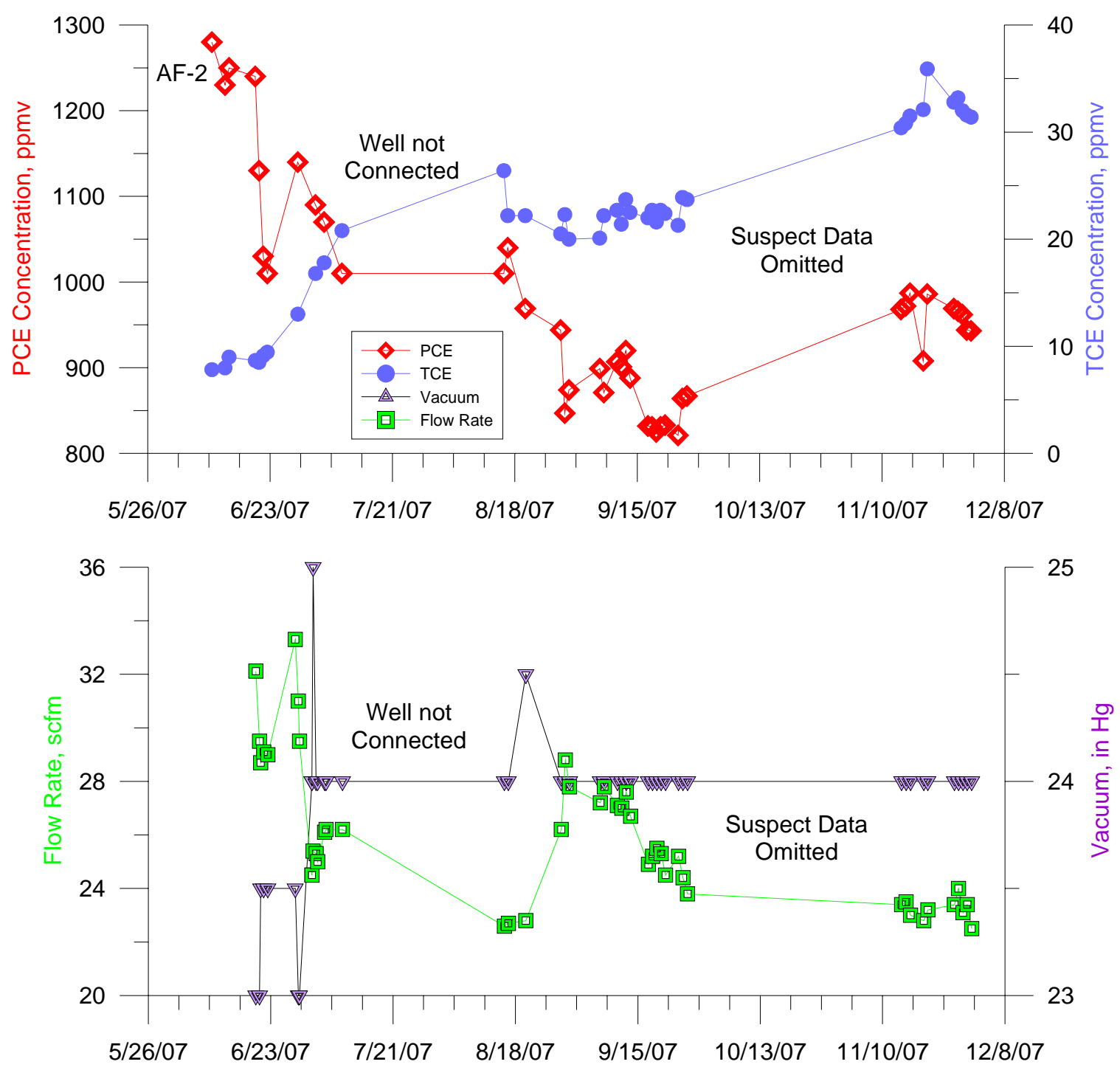

Figure C-1 - Concentration, Flow and Vacuum Data for Well AF-2 
Table C-3 - Concentration and Operation Data for Well AF-4

\begin{tabular}{|c|c|c|c|c|c|}
\hline $\begin{array}{c}\text { Sample Date and } \\
\text { Time } \\
\end{array}$ & $\begin{array}{l}\text { PCE, } \\
\text { ppmv }\end{array}$ & $\begin{array}{l}\text { TCE, } \\
\text { ppmv }\end{array}$ & $\begin{array}{l}\mathrm{CO}_{2}, \\
\text { ppmv }\end{array}$ & $\begin{array}{c}\text { Vacuum, } \\
\text { in Hg }\end{array}$ & $\begin{array}{l}\text { Flow } \\
\text { Rate, } \\
\text { scfm }\end{array}$ \\
\hline 6/9/07 16:15 & 1040 & 2.6 & 3330 & $\mathrm{~nm}$ & $\mathrm{~nm}$ \\
\hline 6/12/07 16:04 & 898 & 3.2 & 3280 & $\mathrm{~nm}$ & $\mathrm{~nm}$ \\
\hline 6/13/07 14:24 & 970 & 3.7 & 3540 & $\mathrm{~nm}$ & $\mathrm{~nm}$ \\
\hline 6/19/07 14:34 & 569 & 2.6 & 3550 & 25.0 & 10.5 \\
\hline 6/20/07 10:40 & 544 & 2.0 & 3870 & 25.0 & 10.2 \\
\hline 6/20/07 16:40 & $\mathrm{nm}$ & $\mathrm{nm}$ & $\mathrm{nm}$ & 25.0 & 10.7 \\
\hline 6/21/07 10:30 & 872 & 3.7 & 4090 & 24.8 & 11.3 \\
\hline 6/22/07 8:19 & 734 & 5.2 & 3720 & 25.0 & 12.6 \\
\hline 6/28/07 14:33 & $\mathrm{nm}$ & $\mathrm{nm}$ & $\mathrm{nm}$ & 24.5 & 17.8 \\
\hline 6/29/07 8:04 & 792 & 4.4 & 4220 & 25.0 & 11.8 \\
\hline $6 / 29 / 07$ 14:25 & $\mathrm{nm}$ & $\mathrm{nm}$ & $\mathrm{nm}$ & 25.5 & 8.8 \\
\hline $7 / 2 / 07$ 10:30 & $\mathrm{nm}$ & $\mathrm{nm}$ & $\mathrm{nm}$ & 25.0 & 11.1 \\
\hline 7/2/07 10:30 & $\mathrm{nm}$ & $\mathrm{nm}$ & $\mathrm{nm}$ & 25.0 & 11.1 \\
\hline 7/2/07 16:56 & $\mathrm{nm}$ & $\mathrm{nm}$ & $\mathrm{nm}$ & 25.0 & 11.5 \\
\hline 7/3/07 9:34 & 823 & 4.9 & 4260 & 25.0 & 12.9 \\
\hline 7/3/07 18:00 & $\mathrm{nm}$ & $\mathrm{nm}$ & $\mathrm{nm}$ & 25.0 & 12.0 \\
\hline 7/5/07 8:34 & 838 & 6.2 & 4240 & 25.0 & 12.6 \\
\hline $7 / 5 / 07$ 16:20 & $\mathrm{nm}$ & $\mathrm{nm}$ & $\mathrm{nm}$ & 25.0 & 11.8 \\
\hline $7 / 9 / 07$ 10:24 & 724 & 7.8 & 4490 & 25.0 & 10.1 \\
\hline 8/15/07 11:30 & 698 & 12.5 & 6290 & 25.0 & 12.3 \\
\hline 8/16/07 8:45 & 831 & 16.1 & 6080 & 25.0 & 12.4 \\
\hline 8/20/07 8:52 & 781 & 17.0 & 5840 & 25.0 & 12.6 \\
\hline 8/28/07 11:09 & 609 & 11.8 & 6520 & 25.0 & 12.3 \\
\hline 8/29/07 10:05 & 422 & 7.1 & 5010 & 25.0 & 14.1 \\
\hline 8/30/07 8:29 & 428 & 6.7 & 5020 & 25.0 & 10.8 \\
\hline 9/6/07 9:51 & 475 & 8.3 & 5920 & 25.5 & 8.5 \\
\hline 9/7/07 8:06 & 515 & 8.1 & 5920 & 25.5 & 8.9 \\
\hline 9/10/07 8:22 & 558 & 9.6 & 5940 & 25.5 & 8.2 \\
\hline 9/11/07 8:28 & 557 & 9.3 & 5840 & 25.5 & 8.3 \\
\hline 9/12/07 8:51 & 589 & 8.9 & 5860 & 25.5 & 8.8 \\
\hline 9/13/07 8:29 & 590 & 9.1 & 5910 & 25.0 & 9.5 \\
\hline 9/17/07 10:10 & 465 & 9.4 & 5400 & 25.0 & 8.4 \\
\hline 9/18/07 8:57 & 515 & 9.5 & 5770 & 25.0 & 10.8 \\
\hline 9/19/07 8:47 & 508 & 9.7 & 5850 & 25.0 & 9.9 \\
\hline 9/20/07 8:00 & 514 & 9.8 & 5700 & 25.0 & 12.0 \\
\hline 9/21/07 8:11 & 521 & 9.9 & 5760 & 25.0 & 11.8 \\
\hline 9/24/07 8:06 & 541 & 10.3 & 5800 & 25.0 & 11.7 \\
\hline 9/25/07 8:11 & 556 & 10.7 & 5760 & 25.0 & 13.4 \\
\hline 9/26/07 9:16 & 577 & 10.9 & 5940 & 25.0 & 11.2 \\
\hline 9/27/07 9:24* & 688 & 15.6 & 5770 & 24.0 & 23.0 \\
\hline 10/1/07 8:39* & 717 & 16.1 & 5740 & 24.5 & 22.5 \\
\hline 10/2/07 8:46* & 748 & 17.0 & 5840 & 24.0 & 23.0 \\
\hline 10/3/07 8:23* & 706 & 15.3 & 5700 & 24.5 & 19.5 \\
\hline 10/4/07 9:02* & 734 & 16.0 & 5700 & 24.5 & 19.6 \\
\hline
\end{tabular}


Table C-3 - Concentration and Operation Data for Well AF-4

\begin{tabular}{|c|c|c|c|c|c|}
\hline $\begin{array}{c}\text { Sample Date and } \\
\text { Time }\end{array}$ & $\begin{array}{l}\text { PCE, } \\
\text { ppmv }\end{array}$ & $\begin{array}{l}\text { TCE, } \\
\text { ppmv }\end{array}$ & $\begin{array}{l}\mathrm{CO}_{2}, \\
\mathrm{ppmv}\end{array}$ & $\begin{array}{l}\text { Vacuum, } \\
\text { in Hg }\end{array}$ & $\begin{array}{l}\text { Flow } \\
\text { Rate, } \\
\text { scfm }\end{array}$ \\
\hline 10/5/07 8:49* & 749 & 17.1 & 5750 & 24.5 & 20.7 \\
\hline 10/8/07 9:00* & 796 & 18.5 & 5820 & 24.0 & 24.0 \\
\hline 10/9/07 8:45* & 815 & 19.9 & 5790 & 24.0 & 27.3 \\
\hline 10/10/07 8:28* & 818 & 20.0 & 5880 & 24.0 & 26.3 \\
\hline 10/11/07 8:54* & 854 & 21.1 & 5900 & 23.5 & 29.2 \\
\hline 10/15/07 8:38* & 863 & 22.0 & 6060 & 24.0 & 28.3 \\
\hline 10/16/07 8:46* & 873 & 22.6 & 6070 & 24.0 & 29.4 \\
\hline 10/17/07 8:00* & 882 & 23.5 & 6050 & 23.5 & 29.9 \\
\hline 10/18/07 8:21* & 884 & 23.7 & 6000 & 23.5 & 30.3 \\
\hline 10/19/07 8:06* & 877 & 23.0 & 5970 & 24.0 & 27.2 \\
\hline 10/22/07 9:02* & 911 & 24.5 & 5990 & 23.5 & 30.9 \\
\hline 10/23/07 8:07* & 909 & 24.8 & 6030 & 23.5 & 30.7 \\
\hline 10/29/07 10:12* & 727 & 16.0 & 5860 & 25.0 & 17.8 \\
\hline 10/30/07 10:56* & 823 & 21.3 & 6060 & 24.0 & 28.3 \\
\hline 10/31/07 9:05* & 838 & 21.9 & 6160 & 24.0 & 30.2 \\
\hline 11/1/07 8:26* & 825 & 21.4 & 6110 & 24.0 & 29.9 \\
\hline 11/2/07 10:04* & 829 & 21.8 & 6190 & 24.0 & 30.8 \\
\hline 11/5/07 8:45* & 823 & 21.1 & 6090 & 24.0 & 30.3 \\
\hline 11/6/07 8:09* & 821 & 21.2 & 6090 & 23.5 & 30.7 \\
\hline 11/7/07 14:11* & 828 & 21.5 & 6150 & 24.0 & 29.9 \\
\hline 11/8/07 8:15* & 465 & 6.2 & 3590 & 25.5 & 7.9 \\
\hline 11/12/07 10:42* & 817 & 22.2 & 6030 & 24.0 & 27.8 \\
\hline 11/13/07 8:30* & 841 & 21.7 & 6020 & 24.0 & 28.4 \\
\hline 11/14/07 8:39 & 724 & 10.2 & 4910 & 25.5 & 7.6 \\
\hline 11/15/07 9:22 & 716 & 10.2 & 4840 & 25.5 & 7.5 \\
\hline 11/16/07 9:22 & 714 & 9.5 & 4800 & 25.5 & 7.5 \\
\hline 11/19/07 10:18 & 678 & 10.1 & 4570 & 25.5 & 7.4 \\
\hline $11 / 20 / 078: 25$ & 716 & 10.2 & 4560 & 25.5 & 7.6 \\
\hline 11/26/07 10:22 & 717 & 9.6 & 4260 & 25.5 & 8.2 \\
\hline 11/27/07 9:08 & 771 & 10.5 & 4230 & 25.5 & 7.9 \\
\hline 11/28/07 9:24 & 729 & 9.8 & 4170 & 26.0 & 7.9 \\
\hline 11/29/07 8:41 & 726 & 9.5 & 4100 & 26.0 & 7.5 \\
\hline 11/30/07 9:36 & 736 & 10.0 & 4060 & 26.0 & 7.6 \\
\hline
\end{tabular}

* Data is suspect. Valve on AF-2 was likely not closed all the way during sampling. 

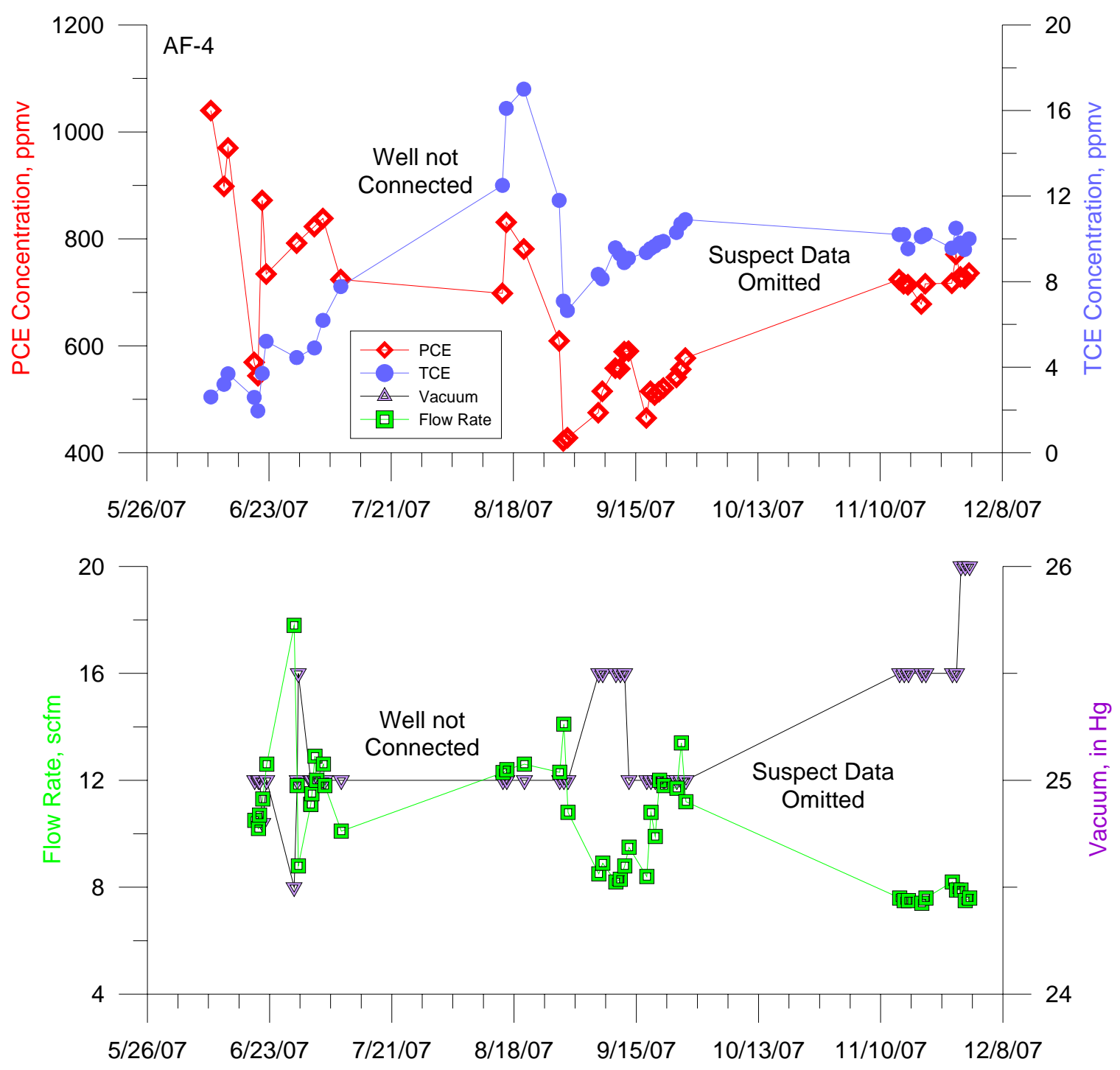

Figure C-2 - Concentration, Flow and Vacuum Data for Well AF-4 
Table C-4 - Concentration and Operation Data for Well AF-5

\begin{tabular}{|c|c|c|c|c|c|}
\hline $\begin{array}{c}\text { Sample Date and } \\
\text { Time }\end{array}$ & $\begin{array}{c}\text { PCE, } \\
\text { ppmv }\end{array}$ & $\begin{array}{c}\text { TCE, } \\
\text { ppmv }\end{array}$ & $\begin{array}{c}\mathrm{CO}_{2}, \\
\text { ppmv }\end{array}$ & $\begin{array}{c}\text { Vacuum, } \\
\text { in Hg }\end{array}$ & $\begin{array}{c}\text { Flow } \\
\text { Rate, } \\
\text { scfm }\end{array}$ \\
\hline 3/8/07 13:34 & $\mathrm{nm}$ & $\mathrm{nm}$ & $\mathrm{nm}$ & 7.0 & 18.0 \\
\hline $6 / 9 / 0716: 15$ & 690 & 19.3 & 3460 & $\mathrm{~nm}$ & $\mathrm{~nm}$ \\
\hline $6 / 12 / 0716: 06$ & 605 & 22.4 & 3420 & $\mathrm{~nm}$ & $\mathrm{~nm}$ \\
\hline $6 / 13 / 0714: 26$ & 523 & 29.7 & 3280 & $\mathrm{~nm}$ & $\mathrm{~nm}$ \\
\hline $6 / 19 / 0714: 36$ & 530 & 30.0 & 3510 & 23.0 & 36.2 \\
\hline $6 / 20 / 0710: 40$ & 363 & 22.3 & 3490 & 23.5 & 26.6 \\
\hline $6 / 20 / 0716: 40$ & $\mathrm{~nm}$ & $\mathrm{~nm}$ & $\mathrm{~nm}$ & 23.5 & 26.1 \\
\hline $6 / 21 / 0710: 32$ & 172 & 13.5 & 3090 & 25.0 & 6.0 \\
\hline $6 / 22 / 078: 21$ & $\mathrm{~nm}$ & $\mathrm{~nm}$ & $\mathrm{~nm}$ & 26.0 & 1.7 \\
\hline $6 / 28 / 0714: 33$ & $\mathrm{~nm}$ & $\mathrm{~nm}$ & $\mathrm{~nm}$ & 25.0 & 18.0 \\
\hline $6 / 29 / 078: 06$ & 349 & 20.1 & 3720 & 25.5 & 8.3 \\
\hline $6 / 29 / 0714: 25$ & $\mathrm{~nm}$ & $\mathrm{~nm}$ & $\mathrm{~nm}$ & 25.5 & 8.8 \\
\hline $7 / 2 / 0710: 30$ & $\mathrm{~nm}$ & $\mathrm{~nm}$ & $\mathrm{~nm}$ & 25.0 & 10.2 \\
\hline $7 / 2 / 0710: 30$ & $\mathrm{~nm}$ & $\mathrm{~nm}$ & $\mathrm{~nm}$ & 25.0 & 10.2 \\
\hline $7 / 2 / 0716: 56$ & $\mathrm{~nm}$ & $\mathrm{~nm}$ & $\mathrm{~nm}$ & 25.0 & 2.7 \\
\hline $7 / 3 / 079: 36$ & 351 & 8.5 & 4000 & 26.0 & 3.0 \\
\hline $7 / 3 / 0718: 00$ & $\mathrm{~nm}$ & $\mathrm{~nm}$ & $\mathrm{~nm}$ & 26.0 & 2.3 \\
\hline $7 / 5 / 078: 36$ & 295 & 5.4 & 3820 & 26.0 & 2.4 \\
\hline $7 / 5 / 0716: 20$ & $\mathrm{~nm}$ & $\mathrm{~nm}$ & $\mathrm{~nm}$ & 26.0 & 3.0 \\
\hline $7 / 6 / 0714: 10$ & $\mathrm{~nm}$ & $\mathrm{~nm}$ & $\mathrm{~nm}$ & 26.0 & 3.2 \\
\hline $7 / 9 / 0710: 26$ & 302 & 5.6 & 4510 & 26.0 & 3.0 \\
\hline
\end{tabular}



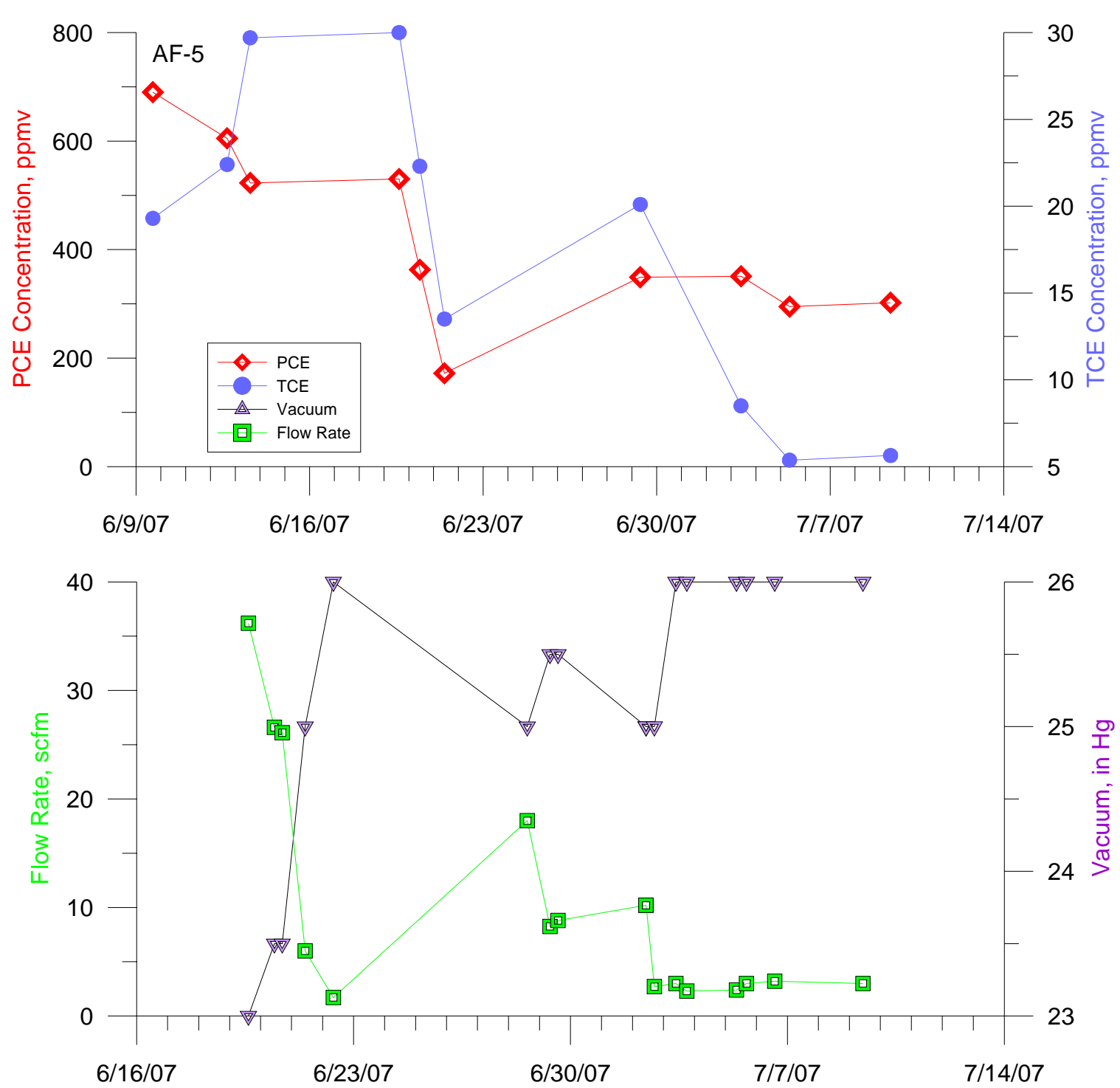

Figure C-3 - Concentration, Flow and Vacuum Data for Well AF-5 
Table C-5 - Concentration and Operation Data for Well AF-7

\begin{tabular}{|c|c|c|c|c|c|}
\hline $\begin{array}{c}\text { Sample Date and } \\
\text { Time }\end{array}$ & $\begin{array}{c}\text { PCE, } \\
\text { ppmv }\end{array}$ & $\begin{array}{c}\text { TCE, } \\
\text { ppmv }\end{array}$ & $\begin{array}{c}\mathrm{CO}_{2}, \\
\text { ppmv }\end{array}$ & $\begin{array}{c}\text { Vacuum, } \\
\text { in } \mathrm{Hg}\end{array}$ & $\begin{array}{c}\text { Flow } \\
\text { Rate, } \\
\text { scfm }\end{array}$ \\
\hline 7/9/07 16:32 & $\mathrm{nm}$ & $\mathrm{nm}$ & $\mathrm{nm}$ & 26.0 & 2.5 \\
\hline $7 / 10 / 079: 32$ & 389 & 42.5 & 3870 & 26.0 & 2.6 \\
\hline $7 / 11 / 079: 30$ & 673 & 58.7 & 3960 & 26.0 & 2.3 \\
\hline $7 / 12 / 0710: 34$ & 1180 & 74.0 & 4080 & 26.0 & 1.6 \\
\hline $7 / 13 / 0710: 50$ & 516 & 27.4 & 3780 & 26.0 & 1.4 \\
\hline $7 / 16 / 0711: 35$ & 1010 & 97.7 & 3640 & 26.0 & $\mathrm{~nm}$ \\
\hline
\end{tabular}
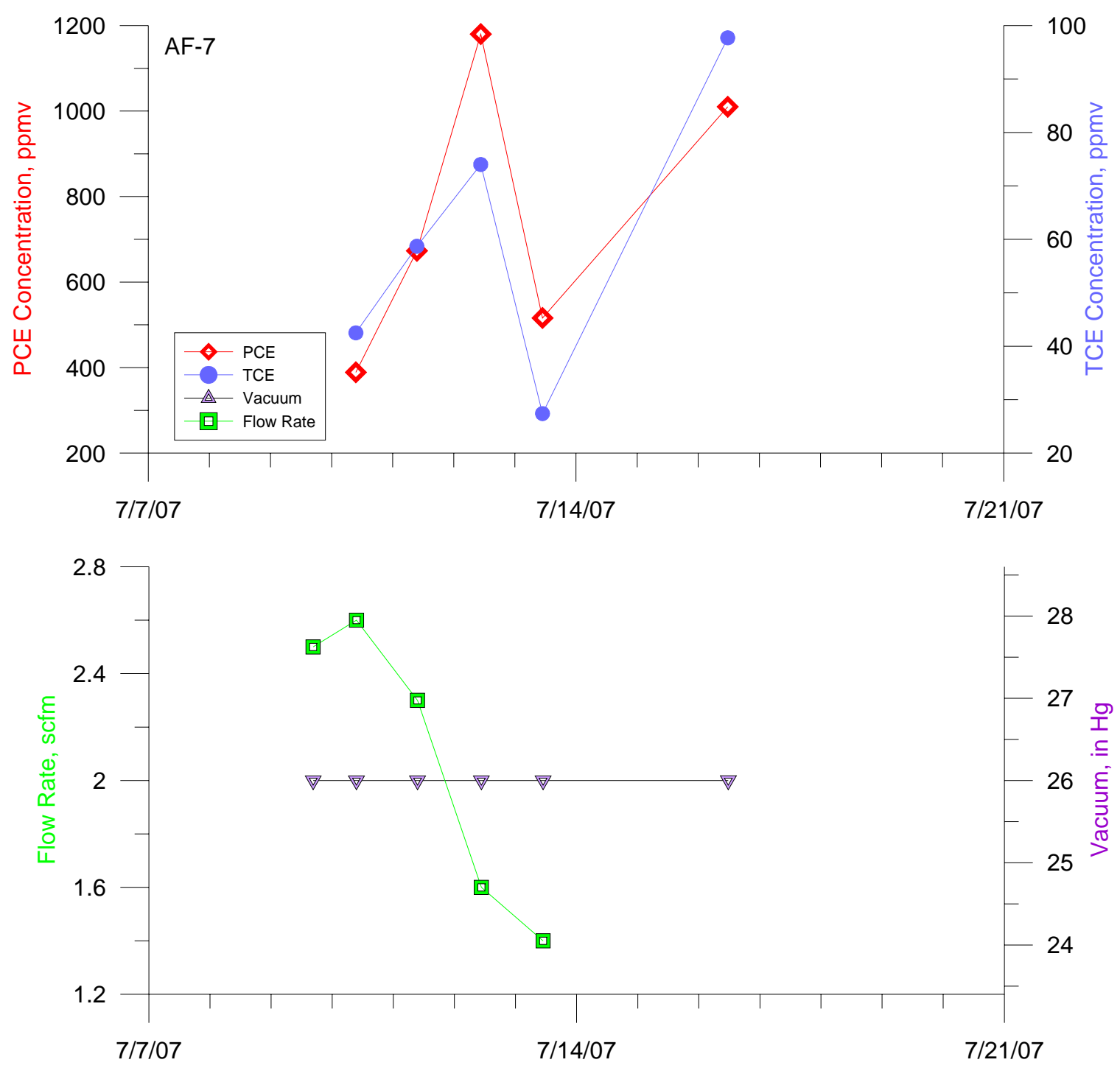

Figure C-4 - Concentration, Flow and Vacuum Data for Well AF-7 
Table C-6 - Concentration and Operation Data for Well AF-8

\begin{tabular}{|c|c|c|c|c|c|}
\hline $\begin{array}{c}\text { Sample Date and } \\
\text { Time }\end{array}$ & $\begin{array}{c}\text { PCE, } \\
\text { ppmv }\end{array}$ & $\begin{array}{c}\text { TCE, } \\
\text { ppmv }\end{array}$ & $\begin{array}{c}\mathrm{CO}_{2}, \\
\text { ppmv }\end{array}$ & $\begin{array}{c}\text { Vacuum, } \\
\text { in Hg }\end{array}$ & $\begin{array}{c}\text { Flow } \\
\text { Rate, } \\
\text { scfm }\end{array}$ \\
\hline $7 / 9 / 0716: 32$ & $\mathrm{~nm}$ & $\mathrm{~nm}$ & $\mathrm{~nm}$ & 18.0 & 74.0 \\
\hline $7 / 10 / 079: 34$ & 140 & 4.9 & 4150 & 18.0 & 74.4 \\
\hline $7 / 11 / 079: 30$ & 194 & 4.4 & 4350 & 18.0 & 73.9 \\
\hline $7 / 12 / 0710: 36$ & 222 & 4.5 & 4430 & 18.0 & 71.9 \\
\hline $7 / 13 / 0710: 55$ & 209 & 4.1 & 4530 & 18.0 & 72.3 \\
\hline $7 / 16 / 0711: 40$ & 161 & 2.8 & 4750 & 18.0 & $\mathrm{~nm}$ \\
\hline
\end{tabular}
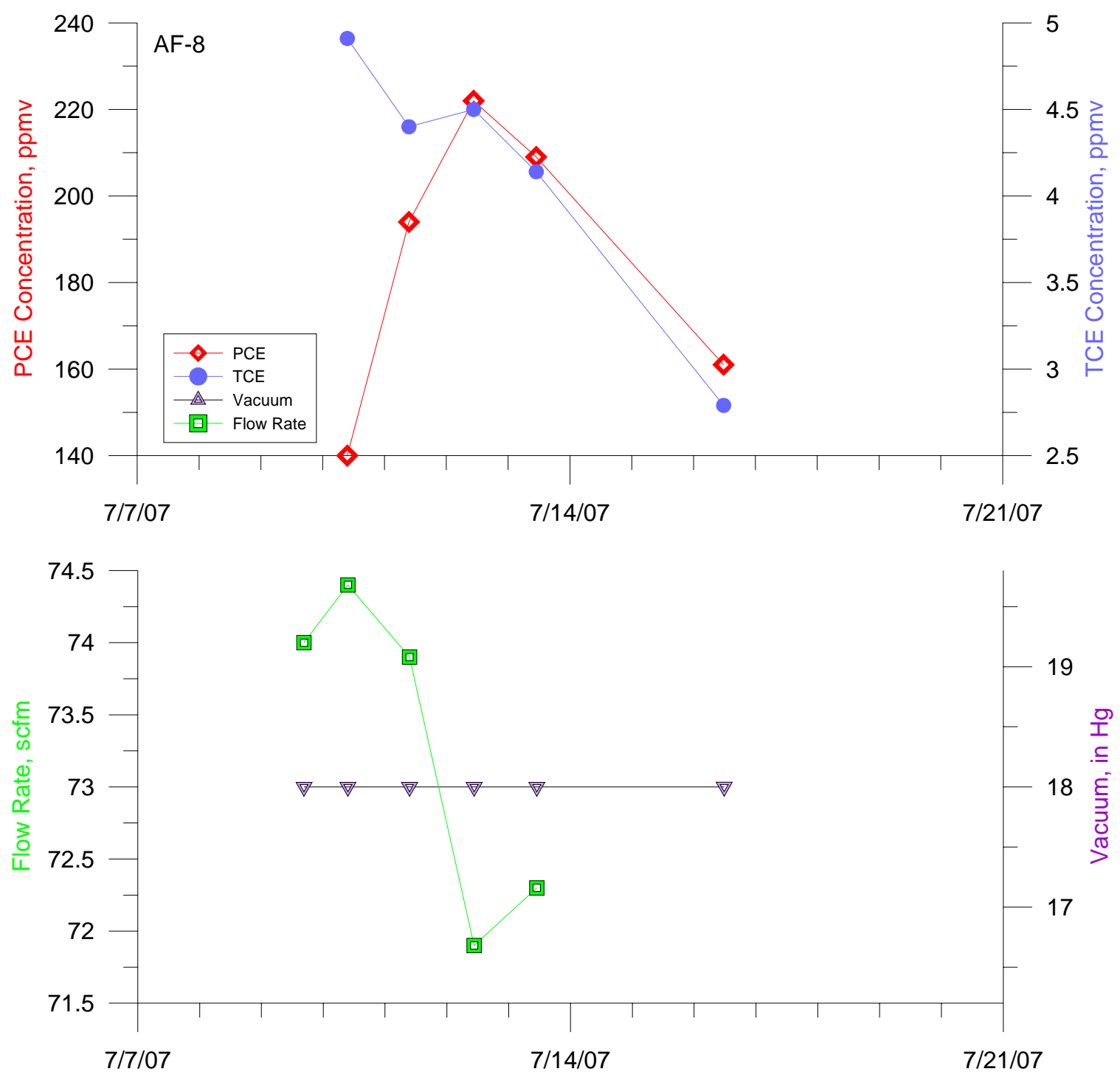

Figure C-5 - Concentration, Flow and Vacuum Data for Well AF-8 


\begin{tabular}{|c|c|c|c|}
\hline \multicolumn{4}{|c|}{ Table C-7 - GC Results from the SVE Unit } \\
\hline $\begin{array}{c}\text { Sample Date and } \\
\text { Time }\end{array}$ & $\begin{array}{l}\text { PCE, } \\
\text { ppmv }\end{array}$ & $\begin{array}{l}\text { TCA, } \\
\text { ppmv }\end{array}$ & $\begin{array}{l}\text { TCE, } \\
\text { ppmv }\end{array}$ \\
\hline $6 / 19 / 2007$ 14:45 & 976.9 & 1.3 & 14.0 \\
\hline $6 / 20 / 2007$ 10:45 & 840.0 & 1.1 & 13.5 \\
\hline 6/21/2007 9:40 & 1047.2 & 0.5 & 8.8 \\
\hline $6 / 29 / 20078: 45$ & 918.5 & 1.0 & 12.6 \\
\hline 7/3/2007 9:30 & 915.6 & 0.8 & 15.3 \\
\hline 7/9/2007 13:30 & 735.7 & 0.9 & 14.8 \\
\hline 7/10/2007 9:45 & 132.8 & 0.3 & 6.5 \\
\hline 7/12/2007 10:30 & 189.5 & 0.3 & 4.4 \\
\hline 7/13/2007 10:45 & 197.3 & 0.4 & 4.5 \\
\hline $7 / 16 / 2007$ 11:30 & 209.5 & 0.4 & 4.9 \\
\hline $7 / 18 / 2007$ 10:15 & 437.6 & 0.4 & 7.6 \\
\hline $7 / 23 / 2007$ 10:30 & 391.2 & 0.4 & 9.1 \\
\hline $7 / 25 / 2007$ 10:15 & 390.6 & 0.4 & 7.3 \\
\hline 7/30/2007 9:15 & 353.7 & 1.3 & 5.8 \\
\hline 7/31/2007 9:40 & 388.5 & 1.7 & 6.2 \\
\hline 8/2/2007 9:45 & 321.4 & 1.2 & 6.1 \\
\hline 8/6/2007 13:45 & 401.1 & 1.6 & 8.4 \\
\hline 8/7/2007 9:45 & 370.0 & 1.4 & 7.1 \\
\hline 8/8/2007 10:15 & 416.4 & 1.6 & 8.3 \\
\hline 8/10/2007 13:00 & 327.3 & 1.5 & 6.8 \\
\hline 8/16/2007 8:27 & 920.7 & 0.8 & 17.6 \\
\hline $8 / 28 / 2007$ 10:59 & 911.3 & 0.8 & 19.5 \\
\hline 8/30/2007 8:19 & 772.8 & 0.8 & 18.5 \\
\hline 9/7/2007 7:56 & 817.3 & 0.8 & 20.5 \\
\hline 9/10/2007 8:08 & 774.6 & 0.8 & 21.9 \\
\hline 9/13/2007 8:17 & 690.9 & 0.9 & 23.3 \\
\hline 9/18/2007 8:48 & 775.8 & 0.9 & 20.5 \\
\hline 9/21/2007 8:00 & 818.7 & 0.8 & 18.9 \\
\hline 9/24/2007 7:54 & 777.6 & 0.8 & 20.0 \\
\hline 9/27/2007 9:19 & 831.5 & 0.9 & 20.7 \\
\hline 10/2/2007 8:41 & 878.6 & 1.1 & 21.1 \\
\hline 10/5/2007 8:43 & 871.2 & 1.2 & 23.2 \\
\hline 10/8/2007 8:55 & 924.4 & 1.4 & 25.0 \\
\hline 10/11/2007 8:51 & 1127.9 & 1.6 & 26.6 \\
\hline 10/16/2007 8:43 & 1004.0 & 2.0 & 28.5 \\
\hline 10/19/2007 8:02 & 1037.0 & 2.0 & 24.8 \\
\hline 10/29/2007 10:01 & 1115.5 & 2.2 & 28.1 \\
\hline 11/2/2007 10:00 & 1030.9 & 1.8 & 24.1 \\
\hline 11/5/2007 8:40 & 806.2 & 1.8 & 22.9 \\
\hline $11 / 12 / 200710: 36$ & 882.6 & 2.3 & 22.7 \\
\hline 11/16/2007 9:14 & 951.9 & 2.0 & 25.4 \\
\hline 11/19/2007 10:30 & 766.1 & 2.1 & 23.0 \\
\hline $11 / 26 / 2007$ 10:15 & 858.1 & 2.6 & 25.6 \\
\hline 11/30/2007 9:29 & 859.7 & 2.4 & 24.5 \\
\hline
\end{tabular}




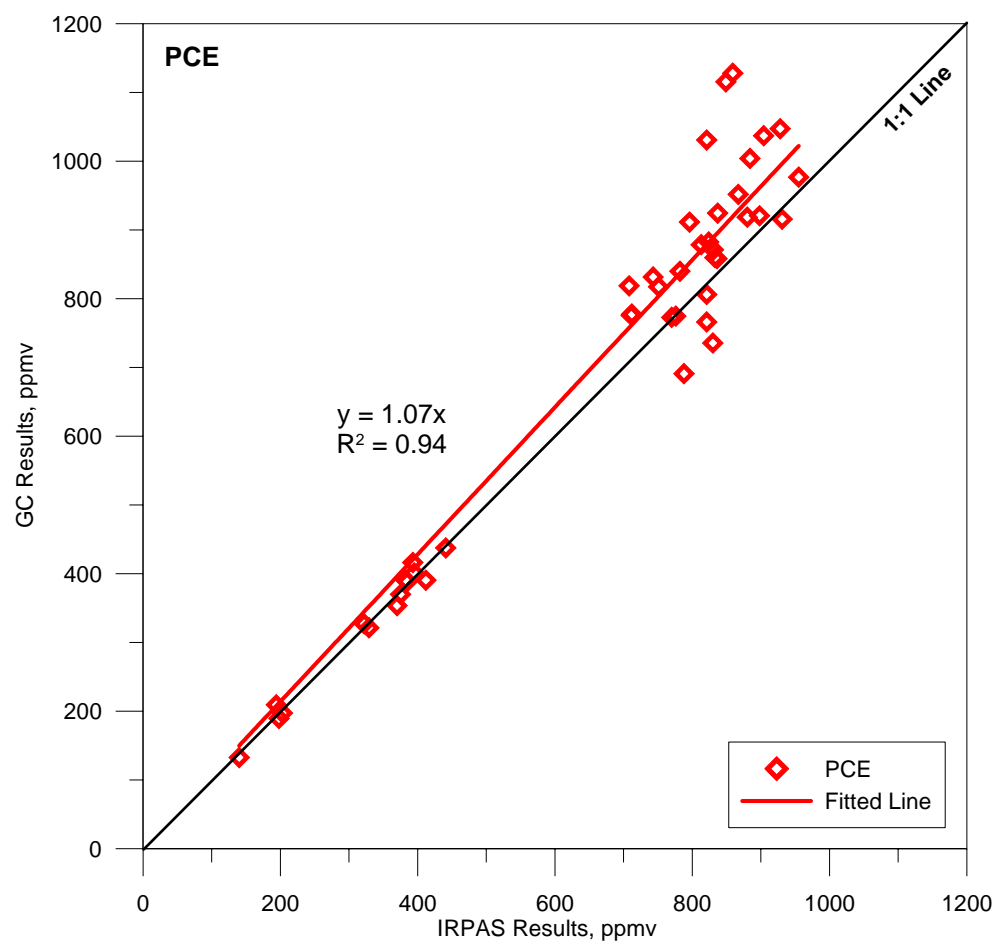

Figure C-6 - Comparison of IRPAS and GC Analytical Results for PCE

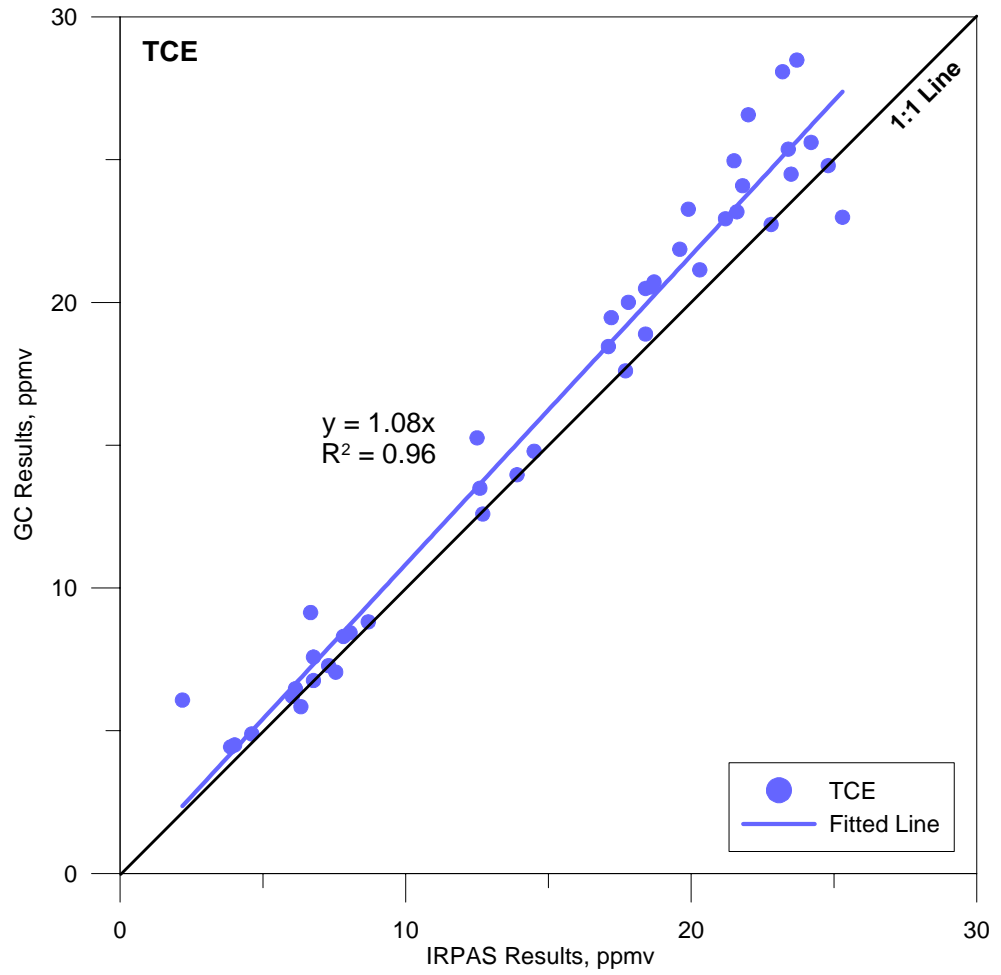

Figure C-7 - Comparison of IRPAS and GC Analytical Results for TCE 